\title{
Vertical Extrapolations of Wind Speed
}

J. C. Doran

J. W. Buck

S. K. Heflick

September 1982

Prepared for the U.S. Department of Energy under Contract DE-AC06-76RLO 1830

Pacific Northwest Laboratory Operated for the U.S. Department of Energy by Battelle Memorial Institute 


\title{
DISCLAIMER
}

This report was prepared as an account of work sponsored by an agency of the United States Government. Neither the United States Government nor any agency thereof, nor any of their employees, makes any warranty, express or implied, or assumes any legal liability or responsibility for the accuracy, completeness, or usefulness of any information, apparatus, product, or process disclosed, or represents that its use would not infringe privately owned rights. Reference herein to any specific commercial product, process, or service by trade name, trademark, manufacturer, or otherwise, does not necessarily constitute or imply its endorsement, recommendation, or favoring by the United States Government or any agency thereof. The views and opinions of authors expressed herein do not necessarily state or reflect those of the United States Government or any agency thereof.

\author{
PACIFIC NORTHWEST I.ABORATORY \\ operated by \\ BATTELLE \\ for the \\ UNITED STATES DEPARTMENT OF ENERGY \\ under Contract DE-AC06-76RLO 1830
}

\begin{tabular}{|c|c|}
\hline \multicolumn{2}{|c|}{ Printed in the United States of America } \\
\hline \multicolumn{2}{|c|}{ Available from } \\
\hline \multirow{2}{*}{\multicolumn{2}{|c|}{$\begin{array}{l}\text { National Technical Information Service } \\
\text { United States Department of Commerce }\end{array}$}} \\
\hline & \\
\hline \multicolumn{2}{|c|}{5285 Port Roval Road } \\
\hline \multicolumn{2}{|c|}{ Springfield, Virginia 22151} \\
\hline \multirow{2}{*}{\multicolumn{2}{|c|}{$\begin{array}{l}\text { NTIS Price Codes } \\
\text { Microfiche A01 }\end{array}$}} \\
\hline & \\
\hline \multicolumn{2}{|c|}{ Printed Copy } \\
\hline & Price \\
\hline Pages & Codes \\
\hline $001-025$ & $\mathrm{~A} 02$ \\
\hline 026-050 & $\mathrm{A} 03$ \\
\hline 051-075 & A04 \\
\hline 076-100 & A05 \\
\hline $101-125$ & A06 \\
\hline $126-150$ & A07 \\
\hline $151-175$ & $\mathrm{~A} 08$ \\
\hline $176-200$ & A09 \\
\hline $201-225$ & A010 \\
\hline $226-250$ & A011 \\
\hline $251-275$ & A012 \\
\hline $276-300$ & A013 \\
\hline
\end{tabular}


J. C. Doran

J. W. Buck

S. K. Heflick

September 1982

Prepared for
the U.S. Department of Energy
under Contract DE-ACO6-76RLO 1830

Pacific Northwest Laboratory

Richland, Washington 99352 
. 


\section{SUMMARY}

The extrapolation of wind speeds and wind speed distributions from a lower to an upper level is examined, with particular emphasis on the power law approach. While the power laws are useful for representing the behavior of winds under a variety of conditions, they are shown to be inherently incorrect and misleading for extrapolations. The law's apparent simplicity nevertheless makes it attractive for certain purposes, and its performance at a number of windy sites is tested. The principal feature seems to be the large degree of scatter found from site to site, and even at a single site from one time to the next. Part of this is attributable to the effects of stability, as is seen by dividing the data into daytime and nighttime periods, but the scatter is by no means eliminated by this division. The behavior of the power law exponents is poorer still in complex terrain. While some general tendencies of these exponents can be found, their use cannot be recommended for anything more than a preliminary or rough estimate of wind speeds.

Extrapolation formulas for Weibull distributions are also tested with the same data base. They are found to work reasonably well in the mean, but the uncertainties present make their use in any particular case somewhat risky.

The use of kites to obtain estimates either of wind speed distributions or power law exponent distributions is simulated. As expected, there is a considerable degree of scatter associated with the results, but the use of kites seems to offer some small possibility of improvement compared to results obtained from the simple extrapolation formulas for Weibull distributions. 


\section{$\checkmark$}

, 


\section{CONTENTS}

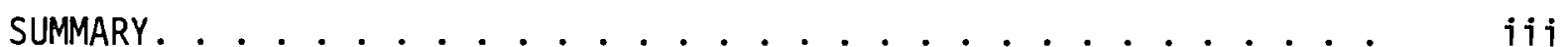

1. BASIC CONCEPTS .............................. 1

1.1 INTRODUCTION. . . . . . . . . . . . . . . . 1

1.2 VERTICAL VARIATION OF MEAN WINDS UNDER "IDEAL" CONDITIONS . 2

1.3 APPROXIMATIONS AND LIMITATIONS OF WIND SPEED EXTRAPOLATIONS. . . . . . . . . . . . . . . 5

1.4 WIND SPEED DISTRIBUTIONS. . . . . . . . . . . . . 6

2. POWER LAW EXTRAPOLATIONS OF MEAN WIND SPEEDS ........... 11

3. EXTRAPOLATION OF WEIBULL PARAMETERS. . . . . . . . . . . . 25

4. SIMULATION OF KITE MEASUREMENTS FOR WIND SPEED EXTRAPOLATIONS. . 37

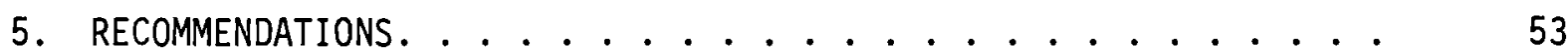

6. REFERENCES ....................... . . . . . . 55 


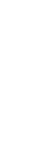




\section{FIGURES}

Diabatic Effects on Wind Profiles. . . . . . . . .

Effects of Roughness Length on Wind Profiles.......

Variation of Shear Exponent With Lower-Level Wind Speed in Simple Terrain for all Hours. ...........

Variation of Shear Exponent With Lower-Level Wind Speed in Simple Terrain for Daylight Hours . . . . . . . . . .

Variation of Shear Exponent With Lower-Level Wind Speed in Simple Terrain for Night Hours. . . . . . . . . . .

Variation of Shear Exponent With Lower-Level Wind Speed in Complex Terrain for all Hours...........

Variation of Shear Exponent With Lower-Level Wind Speed in Complex Terrain for Daylight Hours. . . . . . . . . .

Variation of Shear Exponent With Lower-Level Wind Speed in Complex Terrain for Night Hours............

Variation of Shear Exponent with Lower-Level Wind Speed at Russe11, Kansas, for all Hours; Mean Values $(*)$, Mean $+1 \sigma(+)$, Mean $-1 \sigma(-)$..............

Variation of Shear Exponent With Lower-Level Wind Speed at Russe11, Kansas, for Daylight Hours; Mean Values (*),

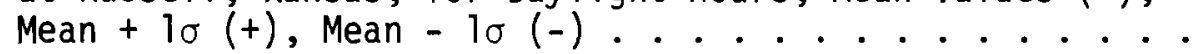

Variation of Shear Exponent With Lower-Level Wind Speed at Russe11, Kansas, for Night Hours; Mean Values (*), Mean $+1 \sigma(+)$, Mean $-1 \sigma(-)$..............

Variation of Shear Exponent With Lower-Level Wind Speed at Minot, North Dakota, for all Hours; Mean Values $(*)$,

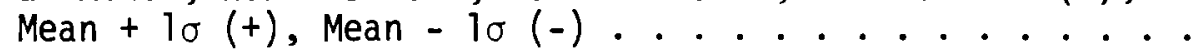

Ratio of Extrapolated to Measured c Values for all Hours.

Ratio of Extrapolated to Measured $c$ Values for Daylight Hours. . . . . . . . . . . . . . . .

Ratio of Extrapolated to Measured $c$ Values for Night Hours. . . . . . . . . . . . . . . . . 
Ratio of Extrapolated to Measured $k$ Values for Daylight

Hours.................... . . . .

Ratio of Extrapolated to Measured $k$ Values for Night

Hours. . . . . . . . . . . . . . . . . . . .

19 Ratio of Extrapolated to Measured $c$ Values for

Simple (S) and Complex (C) Terrain for Night Hours ....

Comparison of Weibull Scale Factors, From Simulated Kite

Flights During All Hours, With Actual Scale Factors for

the Year; Simple Terrain Site (S) and Complex Terrain

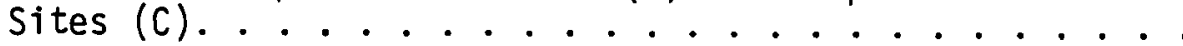

21 Comparison of Weibull Shape Factors, From Simulated Kite Flights During All Hours, With Actual Shape Factors for the Year; Simple Terrain Sites (S) and Complex Terrain Sites (C)..................

22 Comparison of Weibull Scale Factors, From Simulated Kite Flights During Daylight Hours, With Actual Scale Factors for the Year; Simple Terrain Sites (S) and Complex

Terrain Sites (C).................

23 Comparison of Weibull Shape Factors, From Simulated Kite Flights During Daylight Hours, With Actual Shape Factors for the Year; Simple Terrain Sites (S) and Complex Terrain Sites $(C)$. . . . . . . . . . . . . . .

Weibull Distributions for Livingston, Montana, Using Actual Hourly Data for the Year and Simulated Kite Data for all Hours and for Daylight Hours ...........

Weibull Distributions for Minot, North Dakota, Using Actual Hourly Data for the Year and Simulated Kite Data for all Hours and for Daylight Hours.......... .

Comparison of Weibull Scale Factors, From Simulated Kite Flight Alpha Distributions for all Hours, With Actual

Scale Factors for the Year; Simple Terrain Sites $(S)$ and Complex Terrain Sites (C)..............

Comparison of Weibull Shape Factors, From Simulated Kite Flight Alpha Distributions for all Hours, With Actual Shape Factors for the Year; Simple Terrain Sites (S) and Complex Terrain Sites (C). . . . . . . . . . . .

Comparison of Weibull Scale Factors, From Simulated Kite Flight Alpha Distributions for Daylight Hours, With Actual Scale Factors for the Year; Simple Terrain Sites (S) and Complex Terrain Sites (C). . . . . . . . . . . . 
Comparison of Weibull Shape Factors, From Simulated Kite Flight Alpha Distributions for Daylight Hours, With Actual Shape Factors for the Year; Simple Terrain Sites (S) and Complex Terrain Sites (C)............... 


\section{$\underline{\text { TABLES }}$}

Sites for Power Law Computations . . . . . . . . . .

WKY-TV Tower Weibull Coefficients. . . . . . . . .

Ratios of Extrapolated and Measured Weibull Parameters . .

Average Normalized Root Mean Square Errors of KiteSimulated Distributions of $\alpha . . . . . . . . . .$. .

Ratios of Simulated to Actual Weibull Parameters. Simulated parameters are derived from wind speed distributions as approximated by simulated kite measurements . . .

Ratios of Simulated to Actual Weibull Parameters. Simulated parameters are derived from extrapolation of lowerlevel wind speed distributions using kite-derived alpha distributions. . . . . . . . . . . . . . . 


\section{BASIC CONCEPTS}

\subsection{INTRODUCTION}

The extrapolation of wind characteristics from one height to another has long been a subject of both theoretical and practical interest. In the field of wind energy, one of the principal concerns has been the estimation of wind speed distributions at an elevated level, e.g., wind turbine hub height, when data from some lower level are all that are available. In this report this will also be the major concern, al though extrapolations of longitudinal turbulence, directional shear, etc., could also be of interest in evaluating machine performance and integrity.

This report begins with a brief discussion of ideal or, at least, wellbehaved wind profiles whose characteristics are well established in terms of current micrometeorological theory and observations. This is followed by a description of some attempts to "simplify" the mathematical representation of these profiles, and some obvious but often ignored consequences of such attempts. In Section 2, an examination of data from a number of sites representative of a variety of terrain types is given within the framework of these simplified descriptions. Extrapolations of hourly averaged wind speeds are also discussed in that section. In Section 3 the parameters describing wind speed distributions are considered, with particular attention being given to the uncertainties that can arise from extrapolations. The use of kites to obtain estimates of power law exponents and wind speed distributions is treated in Section 4, and Section 5 contains some recommendations.

It is not premature to offer some comments on vertical extrapolations for wind power estimates at this point. The first is that a considerable amount of effort has been expended in this area in the past, and more will, no doubt, be expended in the future. Unhappily, relatively little insight has been gained beyond that which an experienced micrometeorologist might well have provided ten years ago. Much of this report might be subject to the same criticism. However, it is hoped that as a result of this work at least some other investigators will be dissuaded from certain lines of 
inquiry that are inherently unproductive. A second comment is that it seems to be a foolish economy to depend upon extrapolations for decisions that may involve a multimillion dollar investment, when actual measurements might represent a relatively small incremental cost. The danger of extrapolations in complex terrain is particularly severe, as will be shown later, and only the most conservative schemes can be endorsed there. Finally, the atmosphere is a rather complicated system. Further advances in the area of vertical extrapolation of wind characteristics would seem to be served better by taking into account the physics of this system and not by the imposition of some assumption whose principal virtue is its apparent simplicity of application.

Lest this sound too pessimistic, we should note that extrapolation schemes do have their uses and may well be appropriate for preliminary design or energy assessments. The difficulties arise when these schemes are expected to do too much or are applied indiscriminantly without regard for their limitations.

\subsection{VERTICAL VARIATION OF MEAN WINDS UNDER "IDEAL" CONDITIONS}

The behavior of the mean wind in the surface boundary layer has been well established. If buoyant production or dissipation of turbulence is assumed to be negligible compared to the mechanical production of turbulence, and if there is a uniform, upwind fetch several hundred times the height of interest, $z$, then the mean wind velocity, $U(z)$, averaged over a time period of approximately 15 to 60 minutes, is well described by the logarithmic law

$$
U(z)=A \ln \left(z / z_{0}\right)
$$

Here $A$ and $z_{0}$ are two constants that must be determined from the data; $z_{0}$ is known as the roughness length. Equation (1) is valid for $z>z_{0}$, but breaks down as $z$ increases beyond the range in which the shear stress can be considered to be essentially constant. 
"Ideal" conditions are rarely found in the real atmosphere, and a number of modifications have been proposed for Equation (1) in order to describe some of the consequences. The effects of buoyancy are often described in terms of a diabatic correction function $\psi$ such that

$$
U(z)=A\left\{\ln \left(z / z_{0}\right)-\psi\right\} .
$$

The function $\psi$ depends upon the ratio of the height $z$ to a scale length $L$ known as the Monin-Obukhov length, which in turn depends upon the ratio of heat and momentum fluxes. For stable conditions, $\psi$ may be written

$$
\psi=-4.7 \mathrm{z} / \mathrm{L}
$$

In unstable conditions, $\psi$ is somewhat more complicated; a useful tabulation is given in Panofsky (1977). In the limit of $L \rightarrow \infty, \psi \rightarrow 0$, and Equation (2) reduces to Equation (1). For stable atmospheres in which buoyant motion is suppressed, $L$ is positive, while in unstable conditions $L$ is negative.

Figure 1 shows an example of the effects of this diabatic correction on the wind profile, for a site whose roughness length is $0.05 \mathrm{~m}$. It is assumed that a wind speed of $5 \mathrm{~m} / \mathrm{s}$ at a height of $10 \mathrm{~m}$ occurs in each of three cases: neutral stability $(L=\infty)$, moderately unstable conditions $(L=-30 \mathrm{~m})$, and moderately stable conditions $(L=30 \mathrm{~m})$. It has also been assumed that Equation (2) is valid up to a height of $100 \mathrm{~m}$. This assumption may not be justified, but is useful for illustrative purposes. It is clear that an estimate of the wind speed at $100 \mathrm{~m}$ based on Equation (1) could result in substantial errors if it were applied to either of the cases in which $L$ has a finite value.

The height to which Equation (2) remains a useful descriptor of the atmosphere is itself a function of the stability. As the magnitude of $z /|L|$ increases, there is an increasing tendency for Equation (2) to break down, since the wind speed is no longer dominated by surface properties. Under very stable conditions, the constant flux layer may be only a few meters deep, and higher levels of the atmosphere may be effectively decoupled from the surface. 


\section{HEIGHT VARIATION OF WIND SPEED}

\section{STABILITY DEPEDEICE}

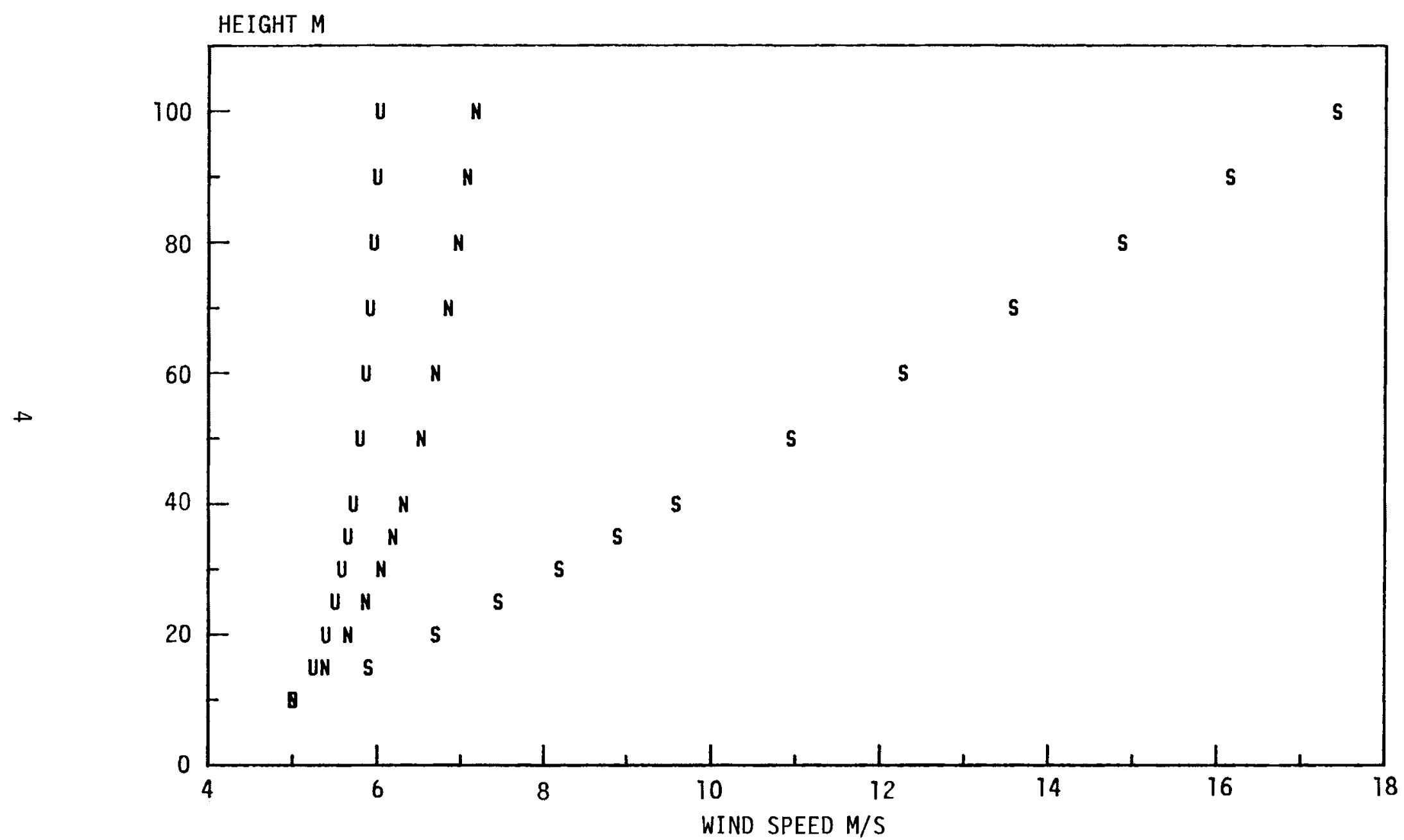

FIGURE 1. Diabatic Effects on Wind Profiles. The three symbols $U, N$ and $S$ denote unstable $(L=-30 \mathrm{~m})$, neutral $(L=\infty)$ and stable $(L=30 \mathrm{~m})$ conditions, respectively. 


\subsection{APPROXIMATIONS AND LIMITATIONS OF WIND SPEED EXTRAPOLATIONS}

A common practice has been to represent the variation of wind speed with height in terms of a power law formulation. Thus, if $U_{1}$ and $U_{2}$ represent the wind speeds at heights $z_{1}$ and $z_{2}$ respectively, then

$$
\frac{\mathrm{U}_{2}}{\mathrm{U}_{1}}=\left(\frac{\mathrm{z}_{2}}{\mathrm{z}_{1}}\right)^{\alpha}
$$

It is clear from Equations (1) and (2) that Equation (4) can only be correct if $\alpha$ is allowed to be a function of $z_{0}, z_{1}, z_{2}$ and stability. Recent demonstrations of this include those by Panofsky (1977) and Mikhail (1977). Despite this, $\alpha$ is often expressed as a constant, e.g., 1/7, or as a function of $z_{0}, z_{1}$ and $U_{1}$. If the latter approach is chosen, $\alpha$ generally approaches either a constant value or zero as $U_{1}$ increases. The rationale for these approximations is that as $U_{1}$ increases, neutral stability is more likely to prevail and diabatic corrections become negligible. The exponent $\alpha$ is then presumed to approach some constant (or zero) value dependent only upon $z_{0}$ and $z_{1}$. In some approximations the $z_{0}$ dependence is also ignored, on the basis of its being relatively smal1. Either approach is clearly incorrect, as a glance at Figure 1 will confirm, since the diabatic effects for unstable and stable conditions are very different. Even if one assumes that moderate-tohigh wind speeds imply neutral stability, the extrapolation of the lower wind speed must still depend on $z_{0}$ and $z_{2}$. Moreover, it is not true that higher wind speeds necessarily imply that diabatic corrections are unimportant.

Consider the examples shown in Figure 1 once again. In each case the wind speed at a height of $10 \mathrm{~m}$ is the same. However, for neutral conditions the effective $\alpha$ between 10 and $50 \mathrm{~m}$ is 0.16 , while it is 0.09 and 0.49 for the moderately stable and unstable conditions, respectively. If $\alpha$ is calculated between 10 and $100 \mathrm{~m}$ for these same cases, the corresponding values are $0.16,0.08$ and 0.54 . Touma (1977) has given other examples of stability effects on power law exponents. 
Figure 2 shows another set of wind profiles, using different roughness lengths but assuming $U(z=10 \mathrm{~m})=5 \mathrm{~m} / \mathrm{s}$ and that neutral stability applies in each case. The $\alpha$ values corresponding to roughness lengths of $0.01,0.05$ and $0.20 \mathrm{~m}$ are $0.13,0.16$ and 0.21 , respectively. Thus, a wind profile developing over smooth terrain can be expected to show significant differences from one developing over rough terrain.

Another complication arises from changes in the nature of the surface upwind of the point of measurement. As was just shown, the wind profile depends upon the surface roughness through the value of $z_{0}$, so any change in the nature of the surface is likely to affect the profile. This is clearly true in neutral conditions, where the effect of $z_{0}$ was seen above; it may be even more evident in diabatic conditions where heat fluxes may differ drastically in a short distance. A well-known example occurs near large bodies of water, where onshore or offshore winds can be altered substantially by such thermal effects. If there is only a simple discontinuity in the surface composition, it is often possible to describe the resulting wind profiles rather well (e.g., Panofsky (1977), Peterson (1969), Rao et a1. (1974)), although their structure becomes more complicated than either Equations (1) or (2) would suggest. As the complexity of the upwind surface increases, so, too, does the complexity of the profile. The result is that many locations defy simple explanations of their observed characteristics, particularly in the detail that estimates of available wind energy might require. In fact, the utility of a roughness length becomes questionable in markedly heterogeneous terrain. One may, perhaps, determine empiricaliy a roughness length for a particular wind direction from observations of winds at two or more levels during neutral conditions. However, this ability may depend upon the availability of the same data at elevated levels that one wishes to estimate by some extrapolation scheme.

\subsection{WIND SPEED DISTRIBUTIONS}

A useful tool for summarizing some wind characteristics at a site is the wind speed frequency distribution. The Rayleigh and Weibull distributions are two analytical forms for distributions that have proven to be 


\section{HEIGHT VARIATION OF WIND SPEED \\ RaCGNESS DEPENOECE}

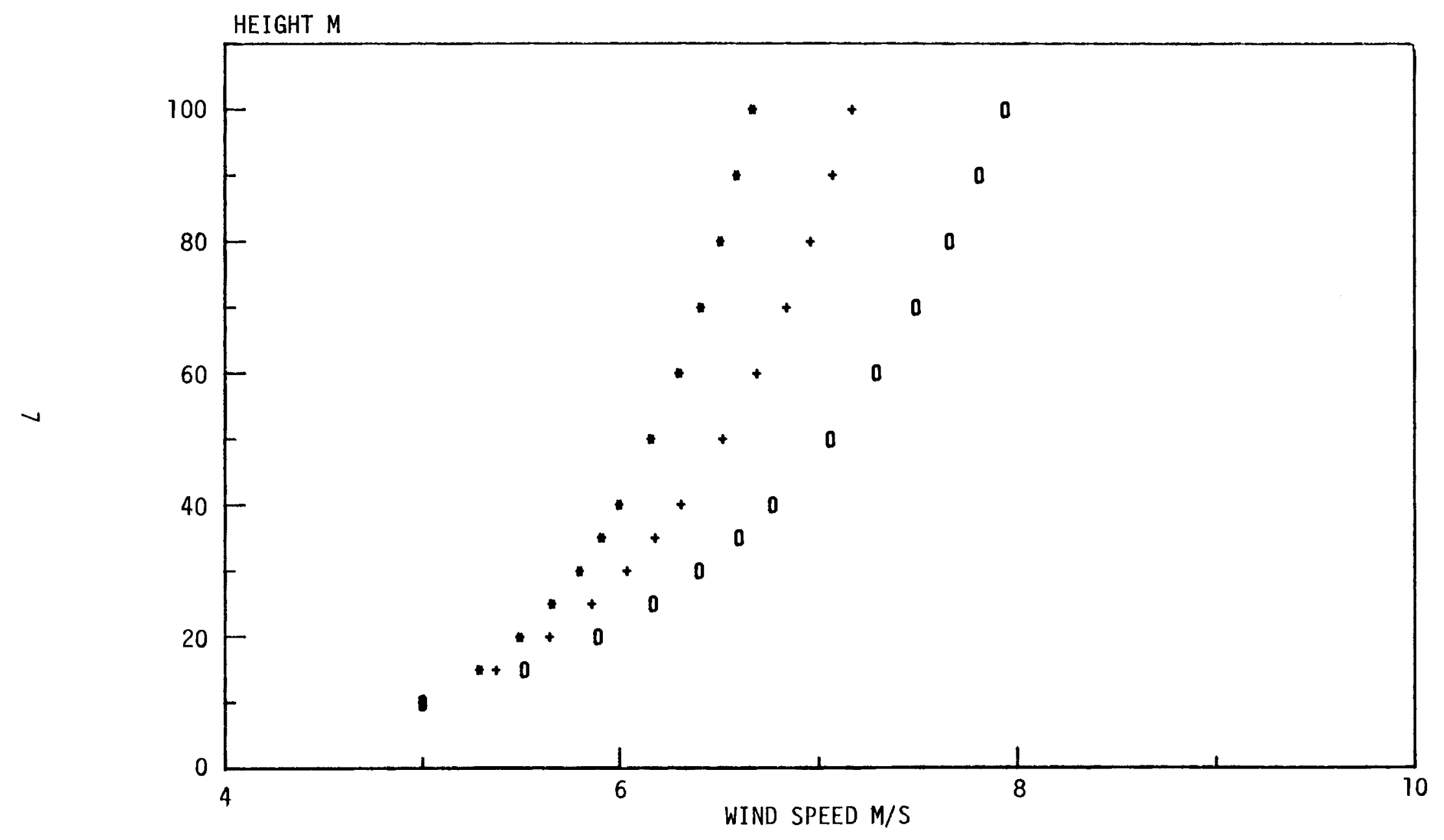

FIGURE 2. Effects of Roughness Length on Wind Profiles. Roughness lengths are $0.01 \mathrm{~m}(*), 0.05 \mathrm{~m}(+)$ and $0.20 \mathrm{~m}(0)$. 
particularly useful and popular. They are one- and two-parameter distributions, respectively, i.e., only one or two parameters are sufficient to describe their behavior. The Weibull distribution may be written as

$$
p(U) d U=\left(\frac{k}{c}\right)\left(\frac{U}{c}\right)^{k-1} \exp \left[-\left(\frac{U}{c}\right)^{k}\right] d U
$$

where $p(U) d U$ is the probability of finding the wind speed in the increment $U$ to $U+d U, c$ is a scale factor related to the mean wind speed $U$ by the relation

$$
\bar{U}=c \Gamma(1+1 / k)
$$

and $k$ is the shape factor, which depends upon the standard deviation of the distribution by

$$
\sigma_{u}^{2}=c^{2}\left\{\Gamma(1+2 / k)-\Gamma^{2}(1+1 / k)\right\}
$$

In Equations (6) and (7), $\Gamma$ is the gamma function. The Rayleigh distribution is a special case of the Weibull distribution with $k=2$.

It should be noted that there is no theoretical or physical reason why an actual wind speed distribution should conform to the Weibull description, and there are actually some arguments as to why it should not. Perhaps it is fortunate, then, that a large number of real distributions are rather well described by Equation (5). This point is noted merely as a reminder that what is true for wind speeds averaged over a relatively short time is likely to be true for wind speed distributions; i.e., the imposition of an extrapolation scheme without a.real physical basis cannot be expected to prove satisfactory all of the time. Happily, however, extrapolation schemes for distributions may actually perform better than extrapolations for individual data. This arises from two restrictions that are characteristic of the former schemes. The first is that the integrated probability of occurrence for all wind speed values is unity, and the second is the assumption that a given 
wind speed and range at one level is closely tied to a second, greater wind speed and range at a higher level. While this need not always be so, as in the case of decoupled flow, it is probably a good approximation in general if the height range is not too large. These constraints on an extrapolation scheme would seem to impose some bounds on its behavior, and thus provide grounds for optimism that its predictions might be reasonable.

There is some motivation, then, for the study of extrapolation schemes. If they are applied intelligently, they can provide useful estimates of the range of behavior that may be encountered at a height not accessible to direct measurements. However, the power law approach advocated for so long by so many is inherently 1 imited, and should not be expected to provide information that is not contained therein. Much of the remainder of this report will be devoted to demonstrating some of these limitations through an examination of data collected at a variety of windy sites. If these demonstrations save future investigators from needless additional effort in this area, the exercise will not have been wasted. 


\section{POWER LAW EXTRAPOLATIONS OF MEAN WIND SPEEDS}

In this section a number of examples of the behavior of power law exponents are given. These examples are derived from data collected at a variety of sites that were instrumented as part of the candidate site evaluation program of the Department of Energy. In all cases, the lower height to be considered is $9.15 \mathrm{~m}$ above the surface while the upper level is at a height of $45.7 \mathrm{~m}$. Thus, the height dependence of extrapolation schemes cannot be assessed with these data; that is covered to some extent in a complementary report prepared by A. Mikhail (1982). The dependence of $\alpha$ on site topography, atmospheric stability and wind speed is considered, however, and a number of conclusions are drawn.

The data were collected using MRI ${ }^{(a)}$ or $C l$ imet ${ }^{(b)}$ cups and vanes. An "instantaneous" reading was recorded on cassette tape every 2 minutes, and 30 of these readings were averaged to provide an hourly average value (Renne and Sandusky, 1980). These hourly averages form the basic data that are considered here.

For convenience, the terrain types were divided into two general classes, simple and complex. Simple terrain refers to open, relatively homogeneous sites that do not have major topographical features nearby that would be expected to affect wind flow. They are usually fairly level, and elevation changes in the vicinity (e.g., a $3-\mathrm{km}$ radius) are gentle and small (e.g., 15 to $20 \mathrm{~m}$ or less). By contrast, complex terrain sites are marked by exceptions to one or more of these characteristics. Table 1 lists the sites used for analysis in this section, and provides a brief description of one or more prominent terrain features for sites that are not classified as simple.

Since detailed measurements or observations that would allow a quantitative determination of stability on an hourly basis at each of these sites were lacking, a severely simplified approach was chosen. The time of local

(a) Meteorology Research, Inc., 464 W. Woodbury Road, A1 tadena, CA 91001

(b) Climet Instrument Company, P.0. Box 151, Redlands, CA 92373 
TABLE 1. Sites for Power Law Computations

Simple Terrain $\quad$ Years of Data

Amarilio, Texas

Clayton, New Mexico

Finley, North Dakota

Fort Sill, Oklahoma

Huron, South Dakota

Meade, Kansas

Russe11, Kansas

2
2
1
1
2
1
2

Complex Terrain

Number of

Years of Data

Tucumcari, New Mexico

San Augustine Pass, New Mexico

Wells, Nevada

Minot, North Dakota

Livingston, Montana

Point Arena, California

CuTebra, Puerto Rico

1
1
1
1
2
2

Terrain Features

High Butte

Ridge Top

Ridge Top

Gently Rolling

Broad River Valley

High Flat Ridge Above Ocean

Hi11y, 1 mi From Ocean

sunrise and sunset at each site was determined by a simple algorithm. These values were then truncated to an integer value of the hour. Daylight hours were defined as beginning two hours after the truncated time of sunrise and as ending two hours before the truncated hour of sunset. An analogous scheme was used to define nighttime hours. This scheme ensured that the only hours included in the daylight data cases occurred when the sun was well above the horizon, and that nighttime hours were chosen only when darkness prevailed. Transition periods were thus avoided to some extent.

While this method is a bit crude, it does serve to discriminate between times when atmospheric conditions are more likely to be stable, i.e., during the night hours, and those times when instability is more apt to prevail, i.e., during daylight. In this way it is possible to summarize the broad effects of stability on power law exponents without having access to a much more extensive and expensive data base. 
The variation of the power law exponent $\alpha$ for these various classifications are summarized in Figures 3 through 8 . Figures 3 through 5 show results obtained over simple terrain for days, nights and all hours while Figures 6 through 8 show corresponding results obtained over complex terrain. In all cases, velocity classes in which there were fewer than 10 hours of observations in a year were excluded. In addition, cases in which the lower level speed was less than $3 \mathrm{~m} / \mathrm{s}$ are not considered.

A number of features are evident. First, the degree of scatter tends to be larger in complex terrain compared to that found in simple terrain. It is not apparent how to systematically describe the effects of complicated topography on $\alpha$, but one interesting characteristic of the data is that the lowest values of $\alpha$ are associated with two sites that are located on ridge tops, viz., Wells, Nevada, and San Augustine Pass, New Mexico. The use of something as crude as a $1 / 7$ power law in locations such as these would result in severe overestimations of the wind speed at the higher level.

A second feature is that there is a discernible difference in the behavior of $\alpha$ during days and nights. This is particularly evident in the lower wind speed categories. In simple terrain, the nighttime values of a are significantly higher than the daytime values in the lower speed ranges, but they approach each other as the wind speed increases. For complex terrain, the trends are not nearly so apparent.

Perhaps most important is the large amount of scatter observed in all cases, regardless of conditions. This suggests that efforts to improve extrapolation techniques are likely to be immensely frustrating so long as one tries to do so in terms of a narrowly defined power law formulation.

A further appreciation of this may be obtained from an examination of Figures 9 through 12. The power law variation obtained at Russe11, Kansas, is plotted, together with the one sigma values of the distribution for each velocity class. The spread in the $\alpha$ values is significant even in this simple terrain case. The uncertainty is particularly noticeable for low wind speeds during the nighttime hours when decoupling of the surface layer from elevated layers is more apt to occur. 
Figure 12 presents similar results for a complex terrain site: Minot, North Dakota. At low wind speeds, the standard deviations in the $\alpha$ values are comparable at Minot and Russell, but the Minot standard deviations tend to be larger for the higher wind speed classes. For all the simple terrain sites the standard deviation in the $\alpha$ values for lower-level wind speeds of 7 to $8 \mathrm{~m} / \mathrm{s}$ averages $44 \%$ of the mean value of $\alpha$; in complex terrain the spread is larger still.

Heald and Mahrt (1981) have suggested rough values for $\alpha$ of 0.3 in stable conditions and 0.05 in unstable conditions. For the simple terrain cases examined here, these values look a bit too high and low, respectively, to be representative. However, the idea of a simple pair of values for the day and night periods has some appeal. In view of the scatter found in a more detailed examination of the behavior of $\alpha$ as a function of wind speed, it is interesting to speculate whether such a simple approach might not be just as satisfactory in its ability to estimate wind speeds at higher elevations.

In view of this uncertainty in the behavior of $\alpha$ from one site to the next, and even from one time to the next at a particular site, it is probably ill-advised to expect anything more than a general description of wind speed behavior at an elevated level using this power law approach. Further advances must rely upon the introduction of a greater degree of reality into the extrapolation scheme. Failing this, it is difficult to see why one would wish to rely upon such a method if the success or failure of a wind energy project depended critically on its results. 


\section{SHEAR EXPONENT DEPENDENCE ON SPEED}

ALL HOURS, SIMPLE TERRAIN $91-457 \%$

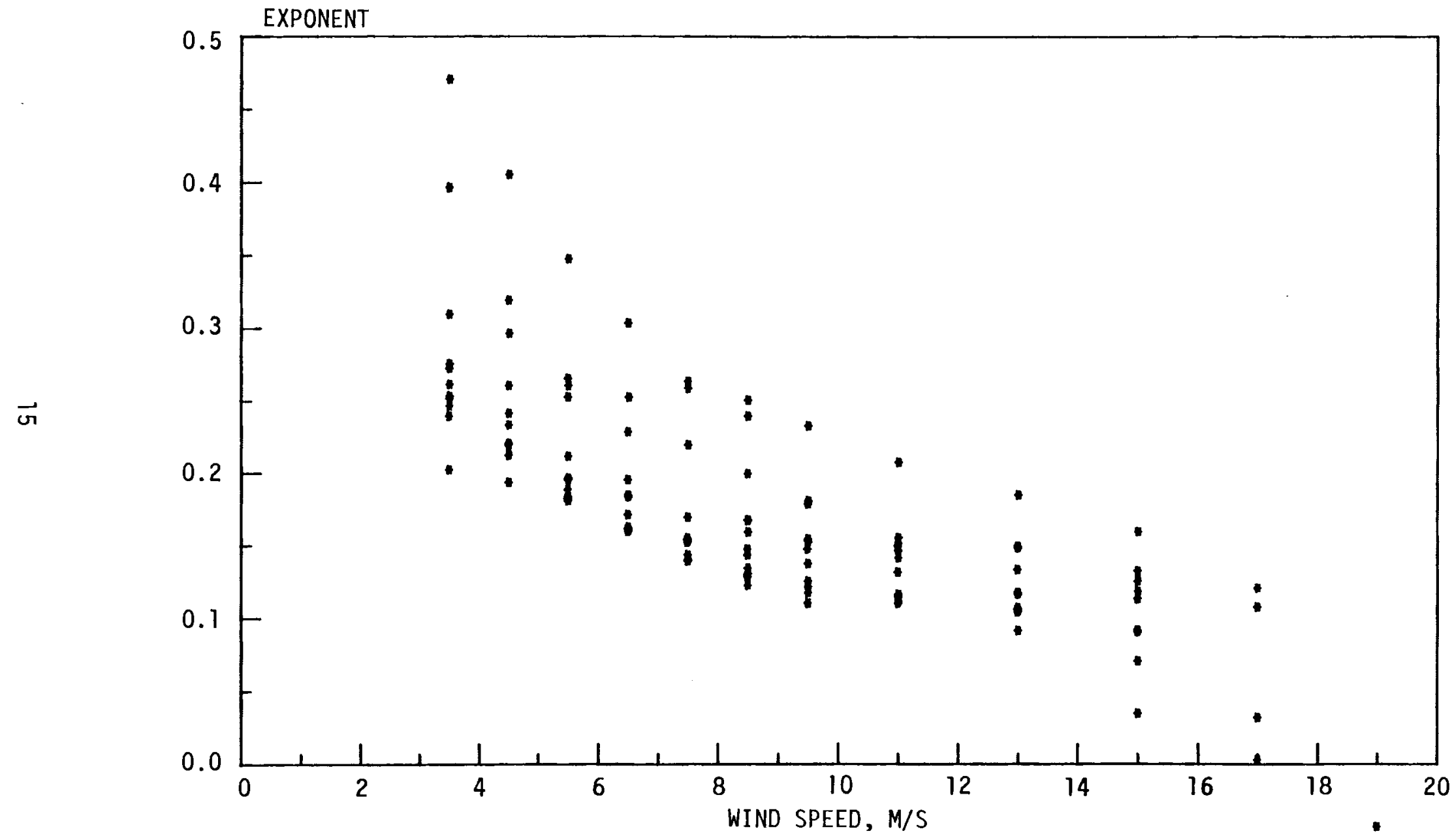

FIGURE 3. Variation of Shear Exponent with Lower-Leve1 Wind Speed in Simple Terrain for all Hours 


\section{SHEAR EXPONENT DEPENDENCE ON SPEED}

DAYS, SIMPLE TERRAIN 9 1-457

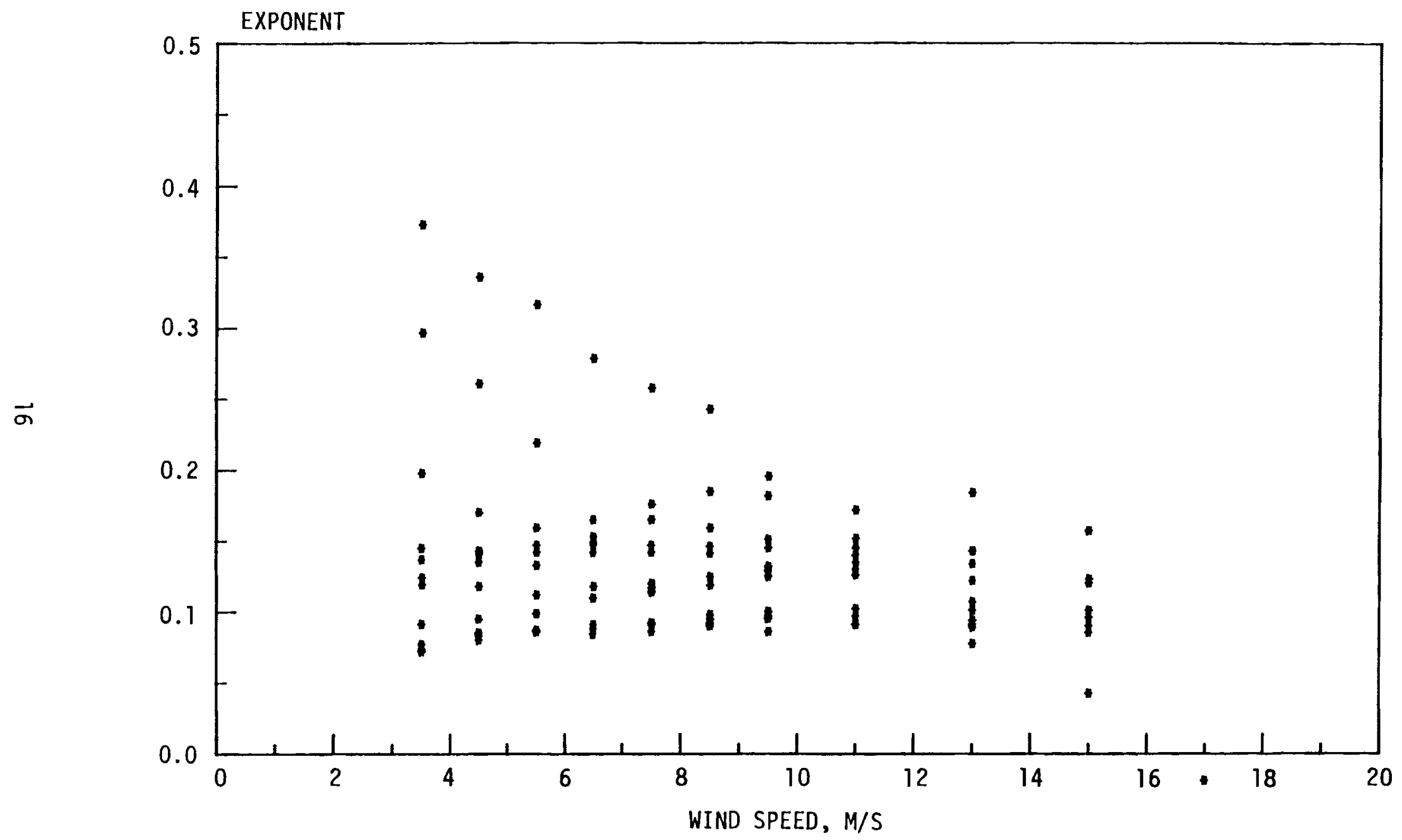

FIGURE 4. Variation of Shear Exponent with Lower-Level Wind Speed in Simple Terrain for Daylight Hours 


\section{SHEAR EXPONENT DEPENDENCE ON SPEED}

NIGHTS, SIIPLE TERRAIN 9.1-45.7 N

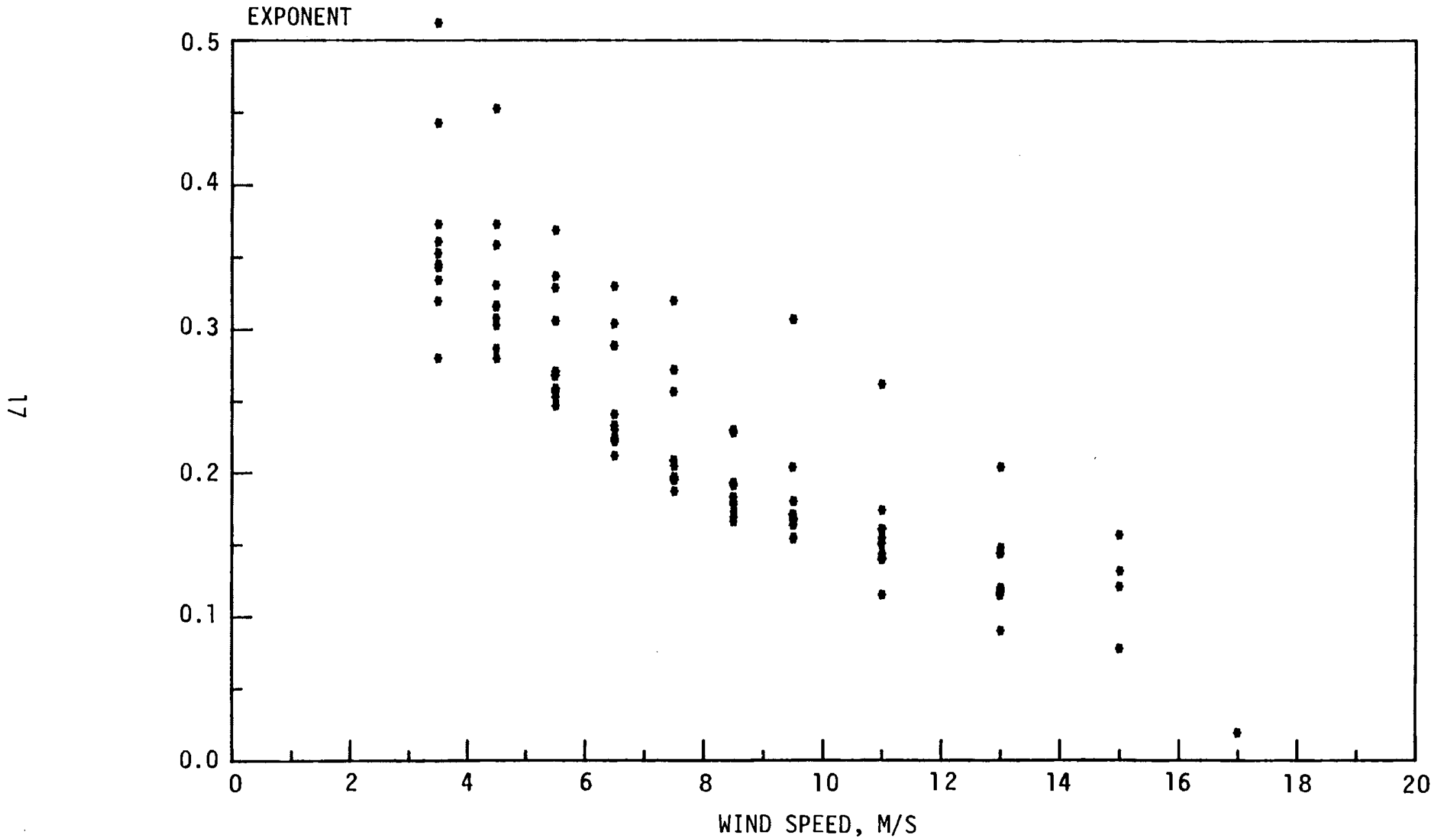

FIGURE 5. Variation of Shear Exponent With Lower-Level Wind Speed in Simple Terrain for Night Hours. 
SHEAR EXPONENT DEPENDENCE ON SPEED

NL HOMS, COMPLX IERRIN Q1-457

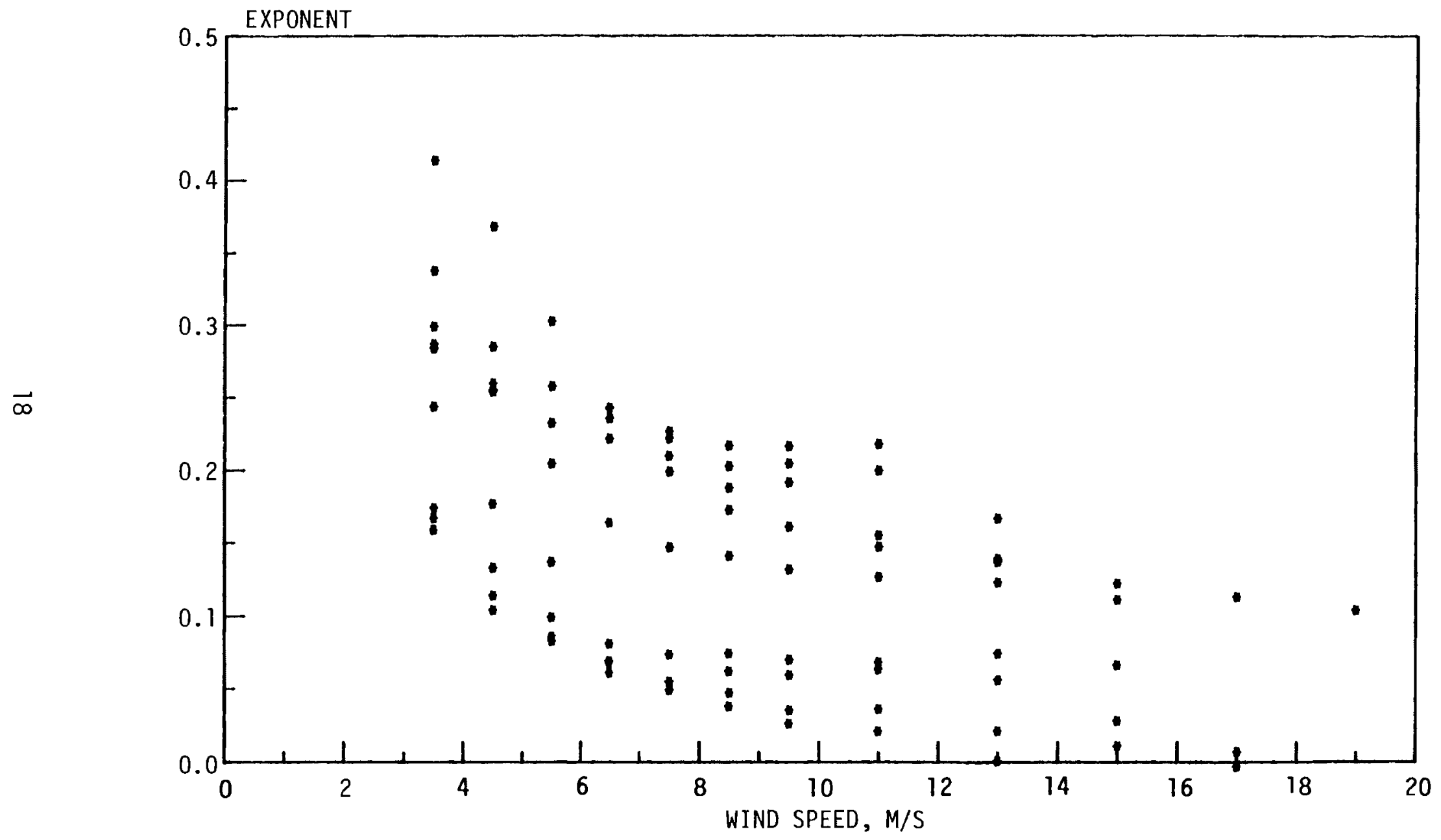

FIGURE 6. Variation of Shear Exponent With Lower-Level Wind Speed in Complex Terrain for all Hours 
SHEAR EXPONENT DEPENDENCE ON SPEED

DAYS. COPLEX IEBPAIN 9.1-45.7 N

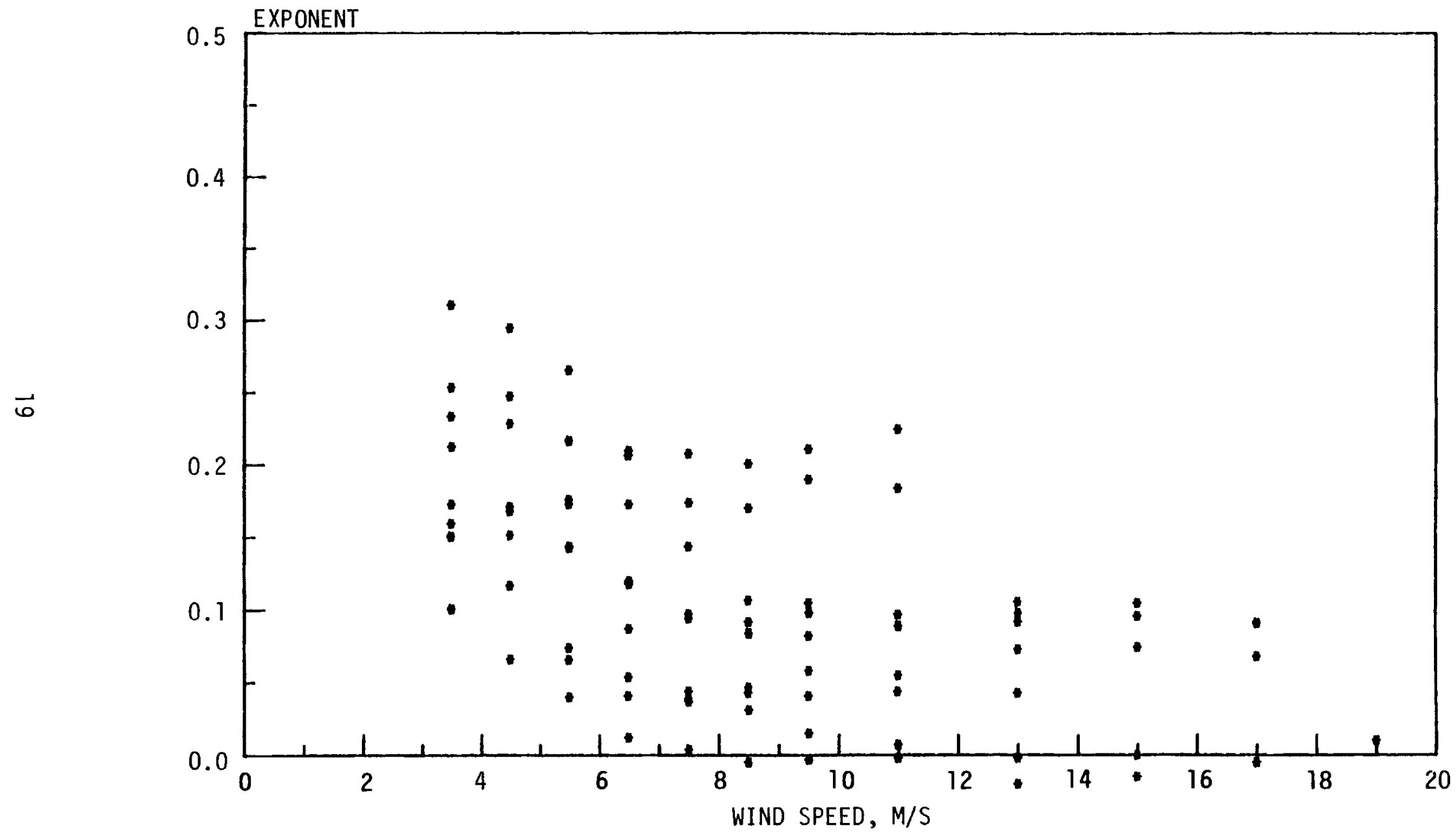

FIGURE 7. Variation of Shear Exponent With Lower-Level Wind Speed in Complex Terrain for Daylight Hours 


\section{SHEAR EXPONENT DEPENDENCE ON SPEED}

NIGTS, COMPLX IEPRAIN Q1-45.7 N

กั

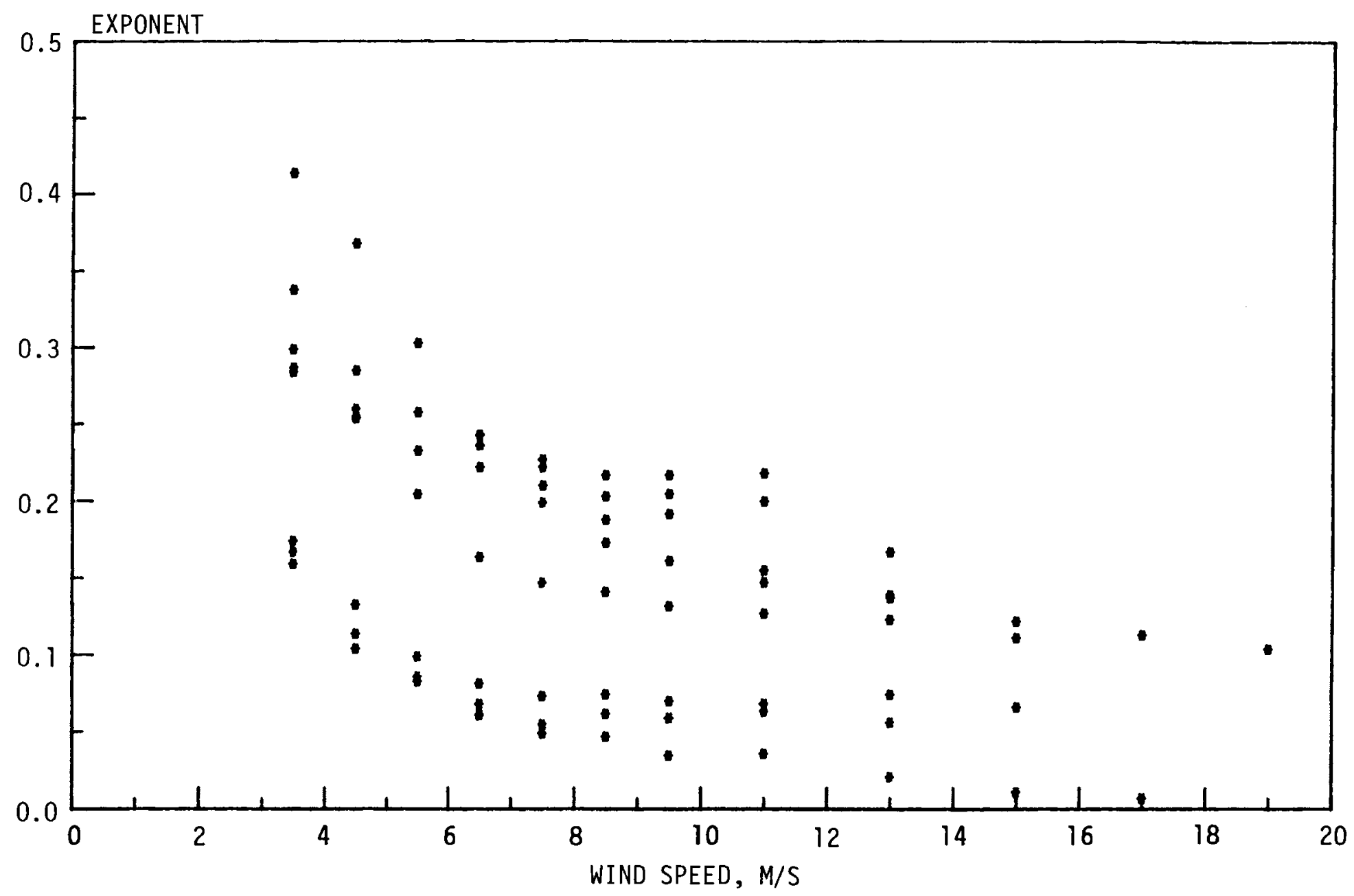

FIGURE 8. Variation of Shear Exponent With Lower-Level Wind Speed in Complex Terrain for Night Hours 
SHEAR EXPONENT DEPENDENCE ON SPEED

1 SIGM BONOS, ALL hORS RUSSELL KNASAS

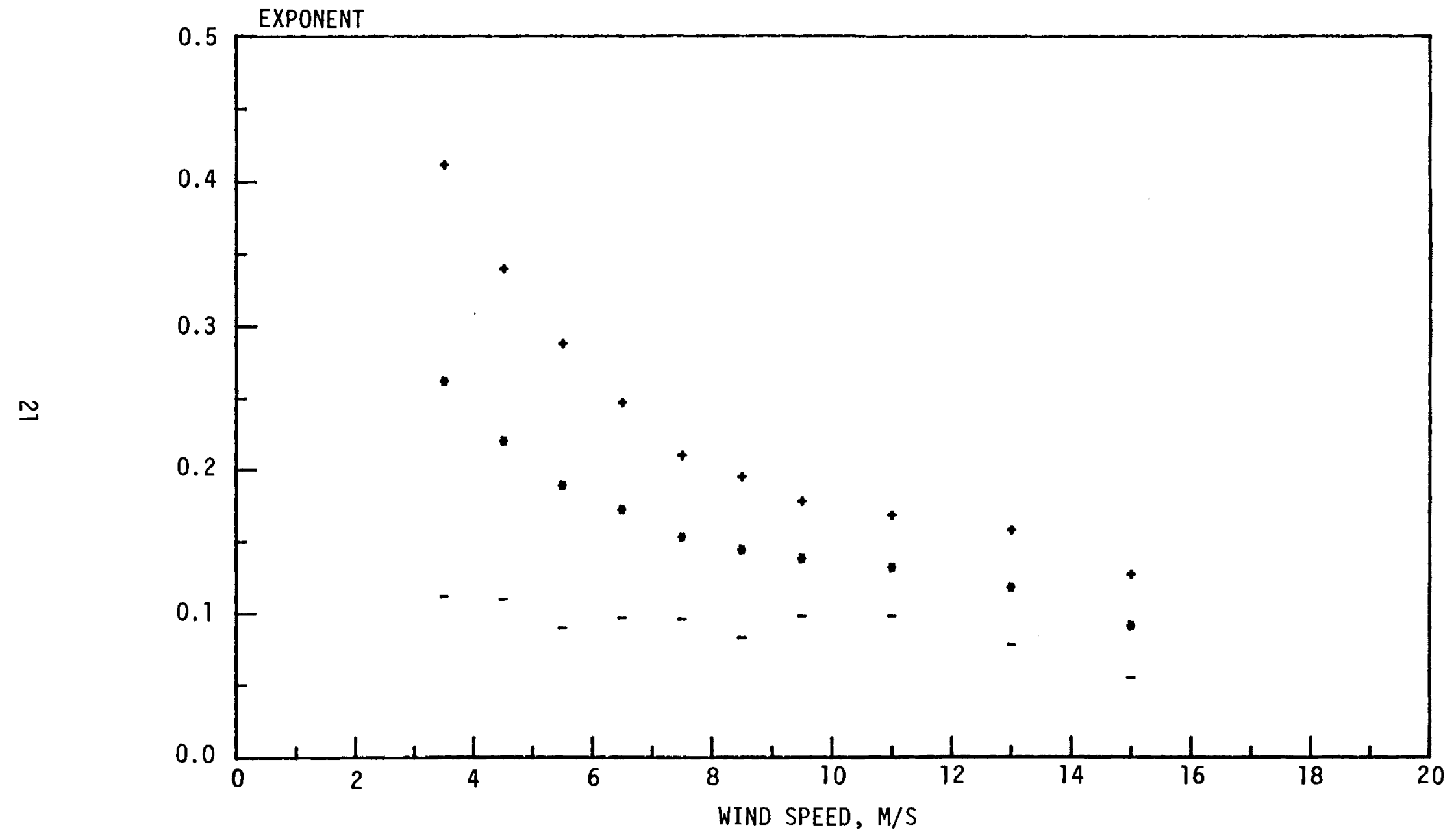

FIGURE 9. Variation of Shear Exponent With Lower-Level Wind Speed at Russel1, Kansas, for all Hours; Mean Values (*), Mean $+10(+)$, Mean $-10(-)$ 


\section{SHEAR EXPONENT DEPENDENCE ON SPEED}

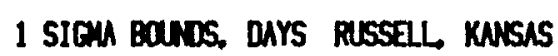

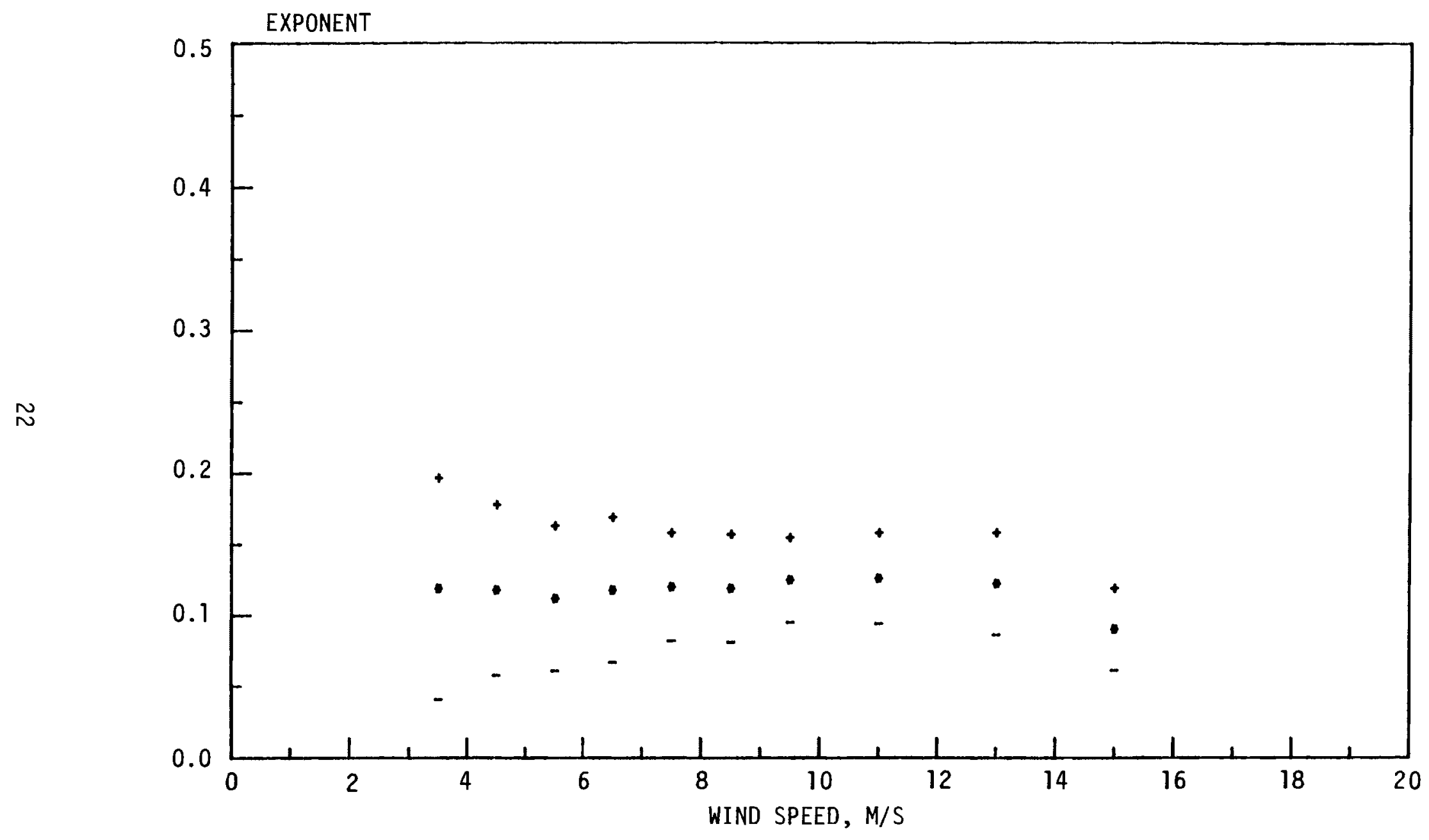

FIGURE 10. Variation of Shear Exponent with Lower-Level Wind Speed at Russe11, Kansas, for Daylight Hours; Mean Values (*), Mean $+1 \sigma(+)$, Mean $-1 \sigma(-)$ 


\section{SHEAR EXPONENT DEPENDENCE ON SPEED}

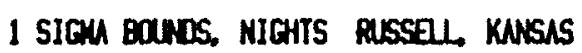

EXPONENT

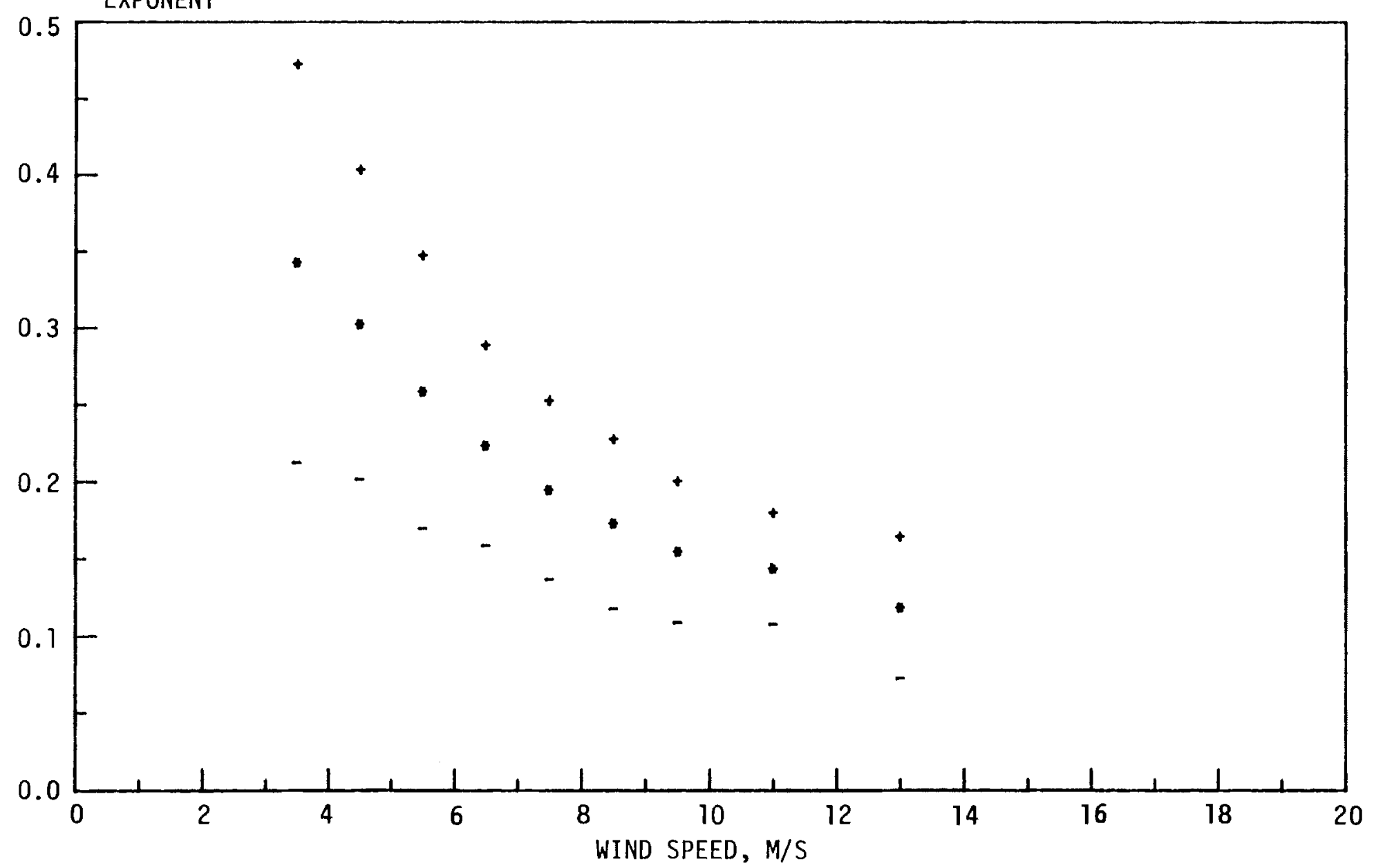

FIGURE 11. Variation of Shear Exponent With Lower-Level Wind Speed at Russe11, Kansas, for Night Hours; Mean Values $(*)$, Mean $+1 \sigma(+)$, Mean $-1 \sigma(-)$ 


\section{SHEAR EXPONENT DEPENDENCE ON SPEED}

1 SIGM BONG, NU MRE, MINT, Kn

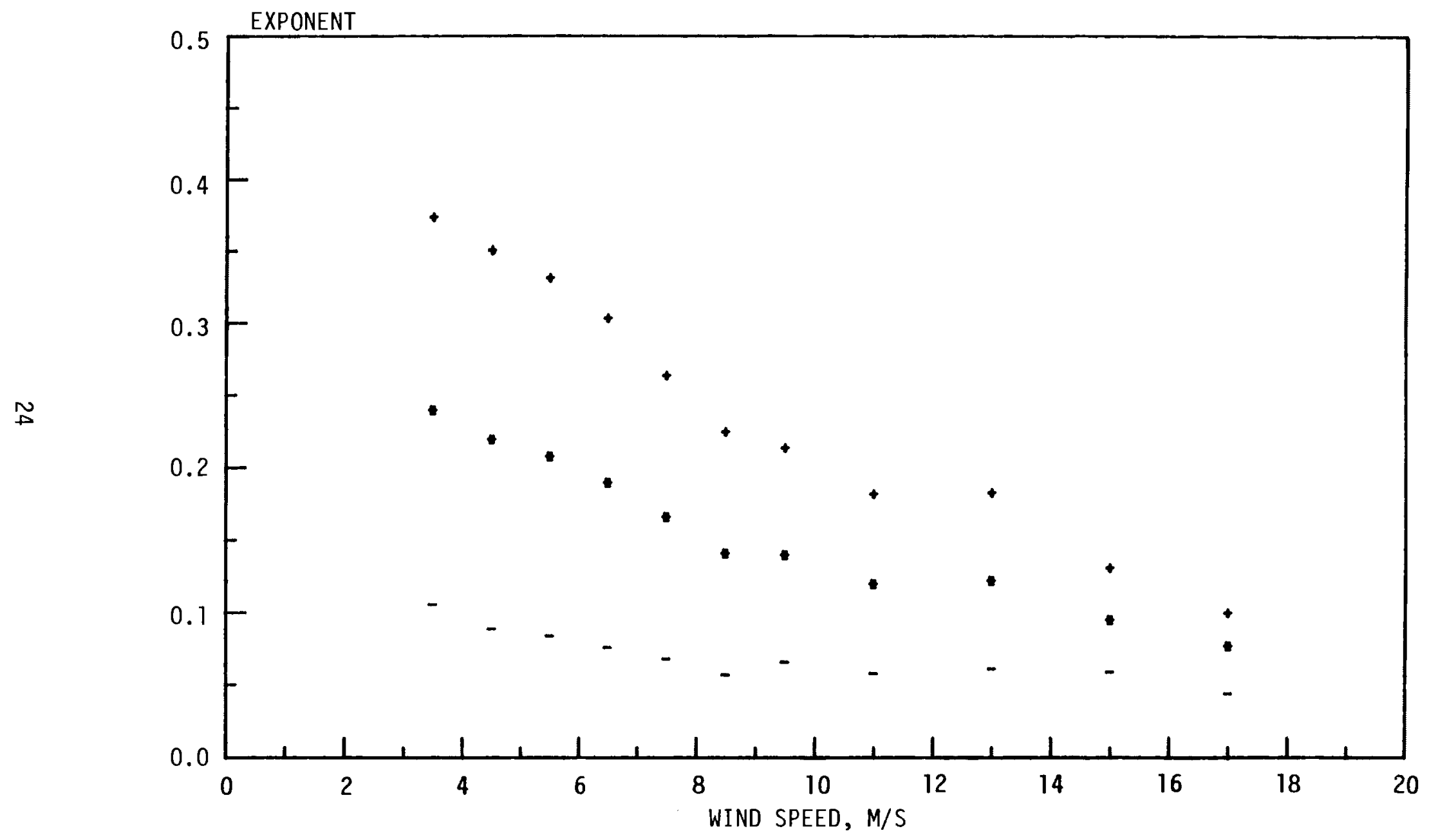

FIGURE 12. Variation of Shear Exponent With Lower-Level Wind Speed at Minot, North Dakota, for all Hours; Mean Values $(*)$, Mean $+1 \sigma(+)$, Mean $-1 \sigma(-)$ 


\section{EXTRAPOLATION OF WEIBULL PARAMETERS}

In Section 1 it was noted that the Weibull distribution has often proved to be a useful analytical approximation to the functional form of the wind speed distribution at a site. Justus and his co-workers $(1976 a, b)$ have described a number of properties of this distribution as it pertains to wind speed applications, including the range of $k$ likely to be encountered for a given mean speed. Of particular relevance to the problem of extrapolations is a paper by Justus and Mikhail (1976a) in which a scheme was proposed whereby the $k$ and $c$ parameters at one height could be used to predict the $k$ and $c$ values at a second height. They based their findings on data from only a few sites; Doran and Verholek (1978) tested their formulas using a larger number of sites. They found good agreement between predicted and actual $c$ and $k$ values in the mean, but also noted that a considerable amount of scatter occurred.

In this section we examine some possible contributions to the scatter. First, all data considered were collected at the same two heights, viz., 9.15 and $45.7 \mathrm{~m}$. Hence, any variation of the extrapolation formulas with height should be removed. By dividing the data into daylight, nighttime and all hour classifications, stability dependences may be investigated to determine whether an explicit treatment of this factor can result in significant improvement. Terrain effects are also discussed.

Before proceeding further, it is appropriate to comment on the use of hourly averages of wind speeds. There is some question about how well such averages can reproduce the proper distribution of wind speeds actually found at a site. For example, would one-minute averages produce a wind speed distribution substantially different from one derived from hourly averages? This problem was considered previously by Doran et a1. (1977) using a rather limited data base. They showed that the mean of a distribution is essentialiy unchanged by such differences, but the variance is reduced as the basic averaging time is increased. However, the change is relatively small for time periods ranging from one minute up to three hours. 
A second test was made for this study, using data collected on the WKY-TV tower near 0klahoma City. Weibull $c$ and $k$ parameters were evaluated using one year's data processed in three ways. In the "standard" approach, data collected every 10 seconds were used to form the wind speed distributions at five levels ranging from 7 to $177 \mathrm{~m}$. In the second approach, these data were averaged to form hourly average values. In the final method, one-minute averages were obtained on the hour and formed the basis for the distribution. The results are summarized in Table 2.

\section{TABLE 2. WKY-TV Tower Weibull Coefficients}

\begin{tabular}{|c|c|c|c|c|c|c|}
\hline \multirow[b]{2}{*}{ Height (m) } & \multicolumn{2}{|c|}{ 10-s Data } & \multicolumn{2}{|c|}{ 1-min Data } & \multicolumn{2}{|c|}{ 1-hr Data } \\
\hline & $c(\mathrm{~m} / \mathrm{s})$ & $k$ & $c(\mathrm{~m} / \mathrm{s})$ & $\mathrm{k}$ & $c(\mathrm{~m} / \mathrm{s})$ & $k$ \\
\hline $\begin{array}{r}7 \\
26 \\
45 \\
77 \\
177\end{array}$ & $\begin{array}{l}4.5 \\
5.2 \\
6.0 \\
7.1 \\
8.4\end{array}$ & $\begin{array}{l}1.68 \\
1.77 \\
1.89 \\
2.03 \\
1.87\end{array}$ & $\begin{array}{l}4.2 \\
5.2 \\
6.1 \\
7.2 \\
9.0\end{array}$ & $\begin{array}{l}1.44 \\
1.73 \\
1.98 \\
2.08 \\
1.99\end{array}$ & $\begin{array}{l}4.3 \\
5.3 \\
6.0 \\
7.1 \\
8.9\end{array}$ & $\begin{array}{l}1.58 \\
2.01 \\
2.11 \\
2.19 \\
2.06\end{array}$ \\
\hline$\overline{c(1 \mathrm{~min}) /}$ & $=1$. & 0.05 & cT & $T$ & $=1.01$ & 0.04 \\
\hline $\bar{k}(1 \min ) / \bar{k}$ & $T=0.9$ & 0.08 & $\overline{\mathrm{k}}(\mathrm{l}$ & $r / \bar{k}$ & $T=1.07$ & 0.08 \\
\hline
\end{tabular}

As can be seen, the results support those obtained from the earlier study. The mean value of the distribution is essentially unaffected, while the variance, reflected in the change in $k$, is affected only in a minor way. Hence, the use of hourly average values can be expected to give a rather good picture of the distribution of wind speeds at a site and the extrapolation properties they may possess.

The formulas to be tested are

$$
\frac{c_{2}}{c_{1}}=\left(\frac{z_{2}}{z_{1}}\right)^{n}
$$


where

$$
n=\left(0.37-0.0881 \ln c_{1}\right) /\left(1-0.0881 \ln \left(z_{1} / 10\right)\right)
$$

and

$$
\frac{\mathrm{k}_{2}}{\mathrm{k}_{1}}=\left(1-0.0881 \ln \left(\mathrm{z}_{1} / 10\right)\right) /\left(1-0.0881 \ln \left(\mathrm{z}_{2} / 10\right)\right) .
$$

Spera and Richards (1979) have suggested a modification of these equations that depends upon the roughness length of the site. As noted in Section 1 , however, the roughness length may be an ill-defined "constant" for a given site in nonhomogeneous terrain. Moreover, its determination may depend upon the availability of the data one wishes to estimate from the extrapolation scheme, so this modification does not seem to offer a significant advantage. This will become even more apparent when the scatter in the data is considered.

Perhaps the simplest measures of the accuracy of Equations (8) through (10) are the ratios of the predicted to the measured Weibull parameters. These are presented in Figures 13 through 18 as a function of the $c$ parameter at the lower level for the $c$ ratios and the $k$ parameter at the lower level for the $k$ ratios. These comparisons are given for daylight hours, nighttime hours and all hours. In each case a line corresponding to a perfect prediction, i.e., a ratio of one, is included for comparison.

The first feature to be noted is the degree of scatter in the results, a characteristic that should hardly be surprising at this stage. The second feature of importance is the systematic biases that are exhibited by the data when they are considered as functions of stability. This is seen in the behavior of $c$, for example, which is overpredicted during daylight hours and underpredicted during the nights. Similar behavior is observed for $k$, while in both cases the mean prediction for all hours is fairly accurate. This behavior is summarized in Table 3 . 


\section{RATIO OF EXTRAPOLATED TO MEASURED C NL hous}

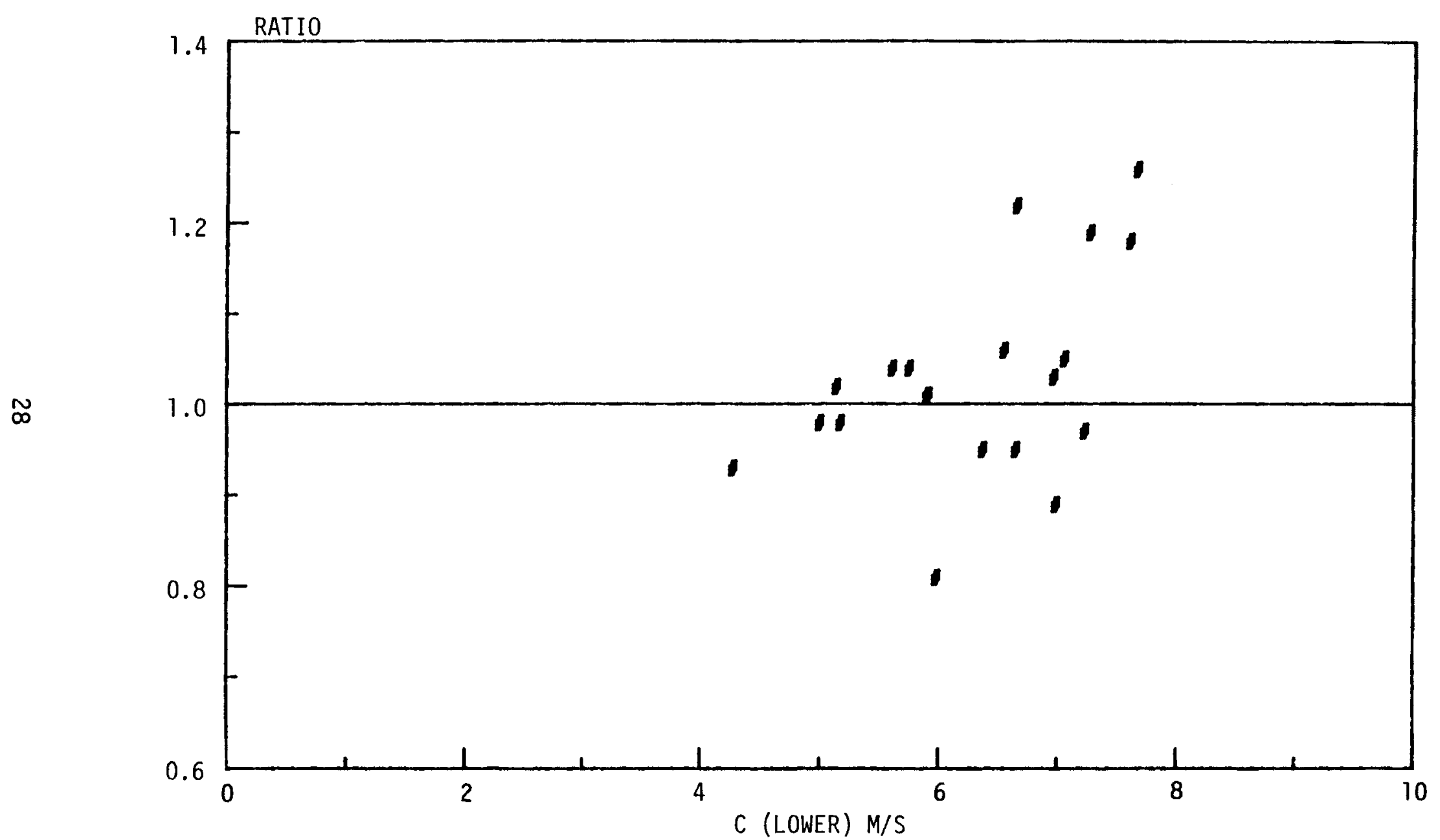

FIGURE 13. Ratio of Extrapolated to Measured c Values for all Hours. Extrapolations are based on Equations (7) and (8). 


\section{RATIO OF EXTRAPOLATED TO MEASURED C}

ans

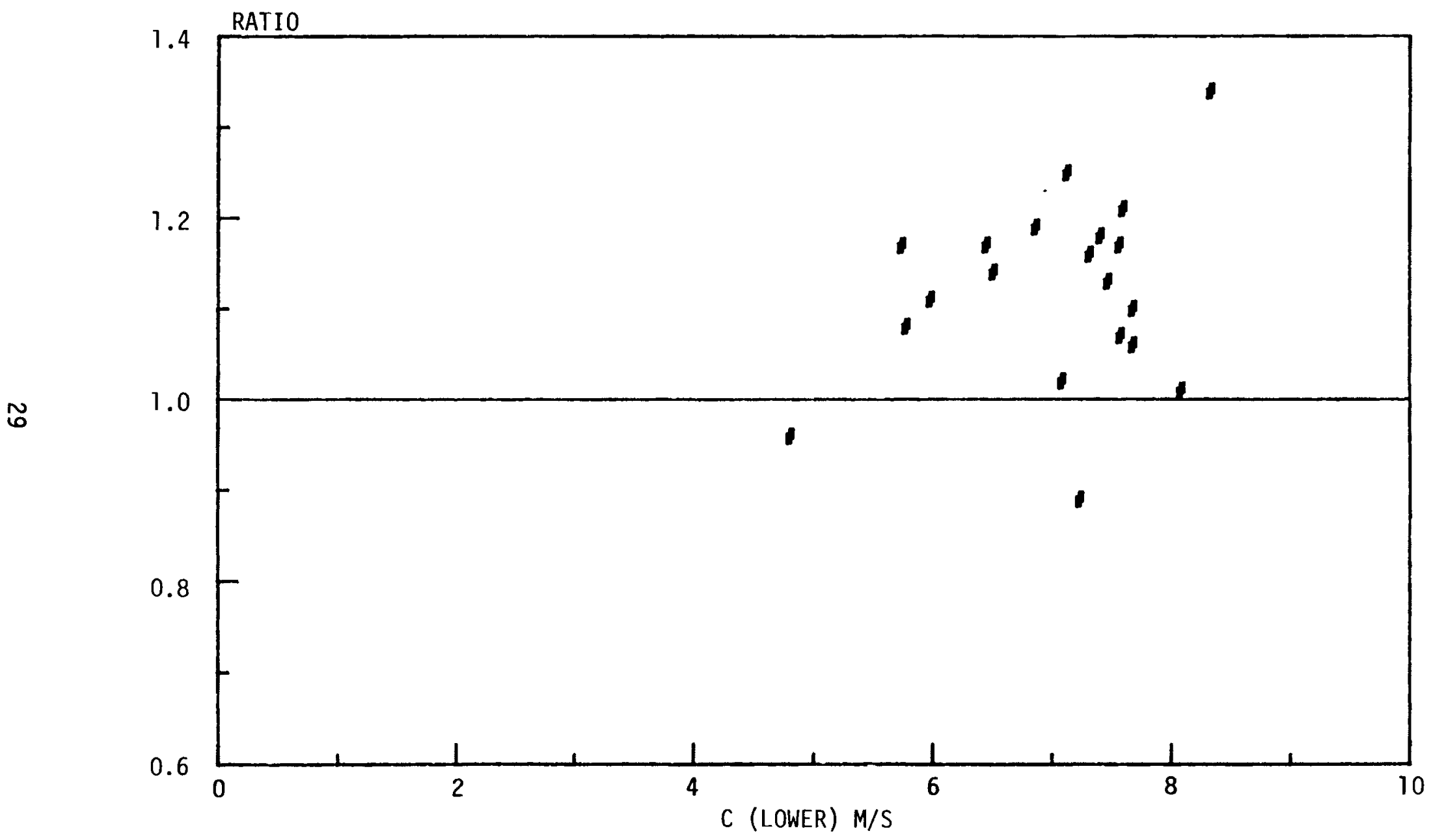

FIGURE 14. Ratio of Extrapolated to Measured $c$ Values for Daylight Hours. Extrapolations are based on Equations (7) and (8). 


\section{RATIO OF EXTRAPOLATED TO MEASURED C}

MGTTS

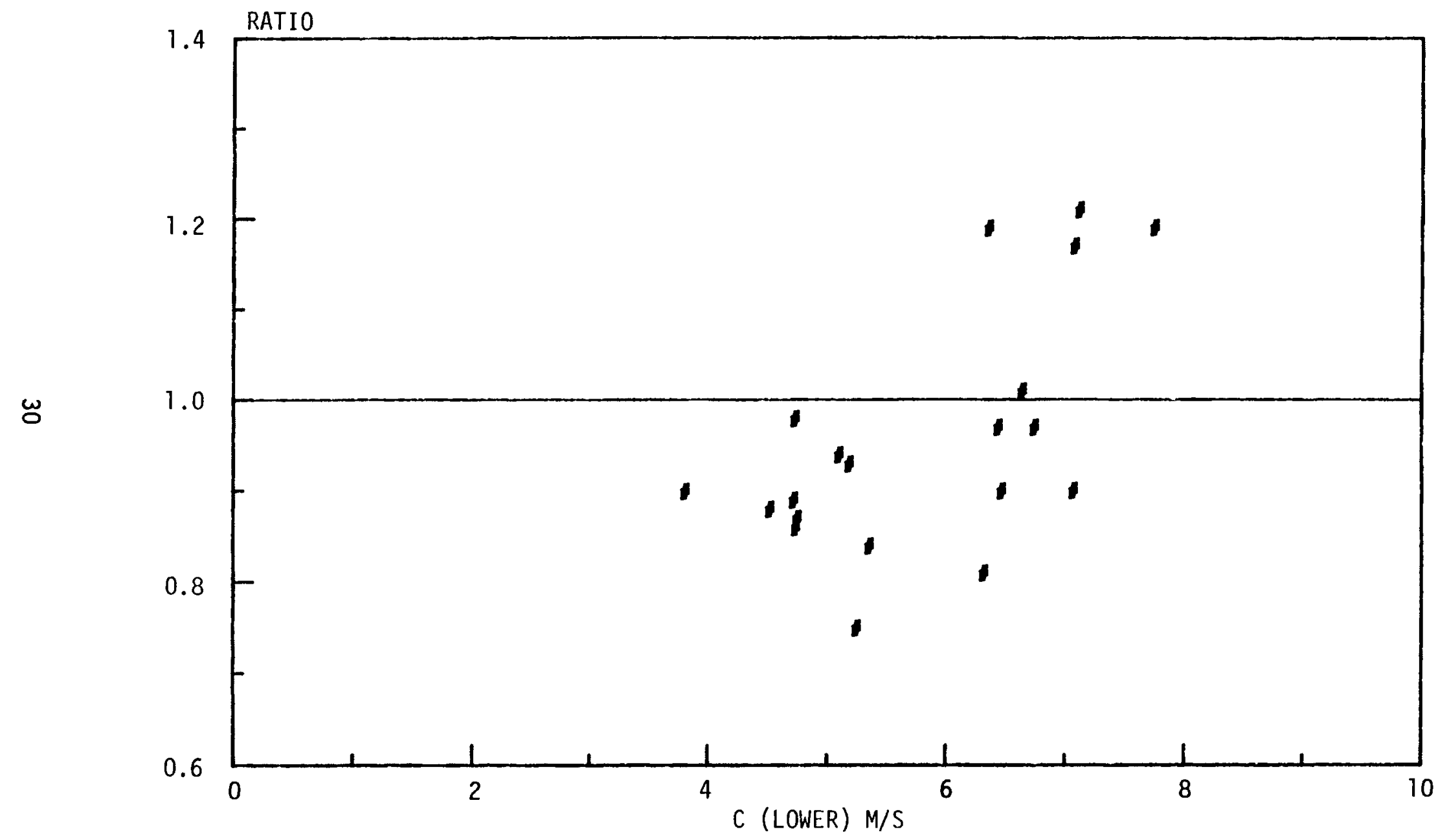

FIGURE 15. Ratio of Extrapolated to Measured c Values for Night Hours. Extrapolations are based on Equations (7) and (8). 


\section{RATIO OF EXTRAPOLATED TO MEASURED $K$}

aurs

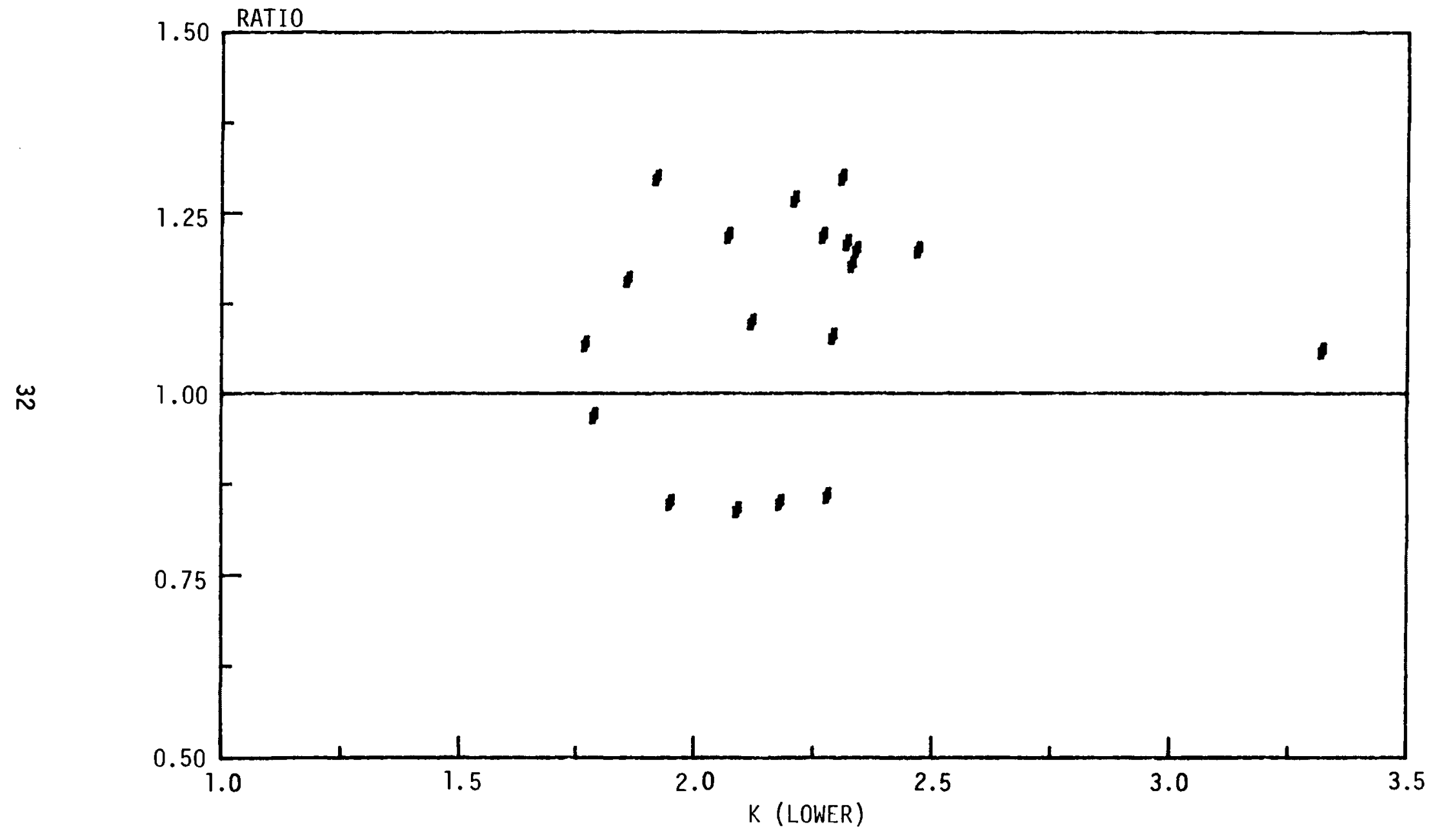

FIGURE 17. Ratio of Extrapolated to Measured $k$ Values for Daylight Hours.

Extrapolations are based on Equation (9). 


\section{RATIO OF EXTRAPOLATED TO MEASURED $K$ \\ Al hilis}

$\underline{\omega}$

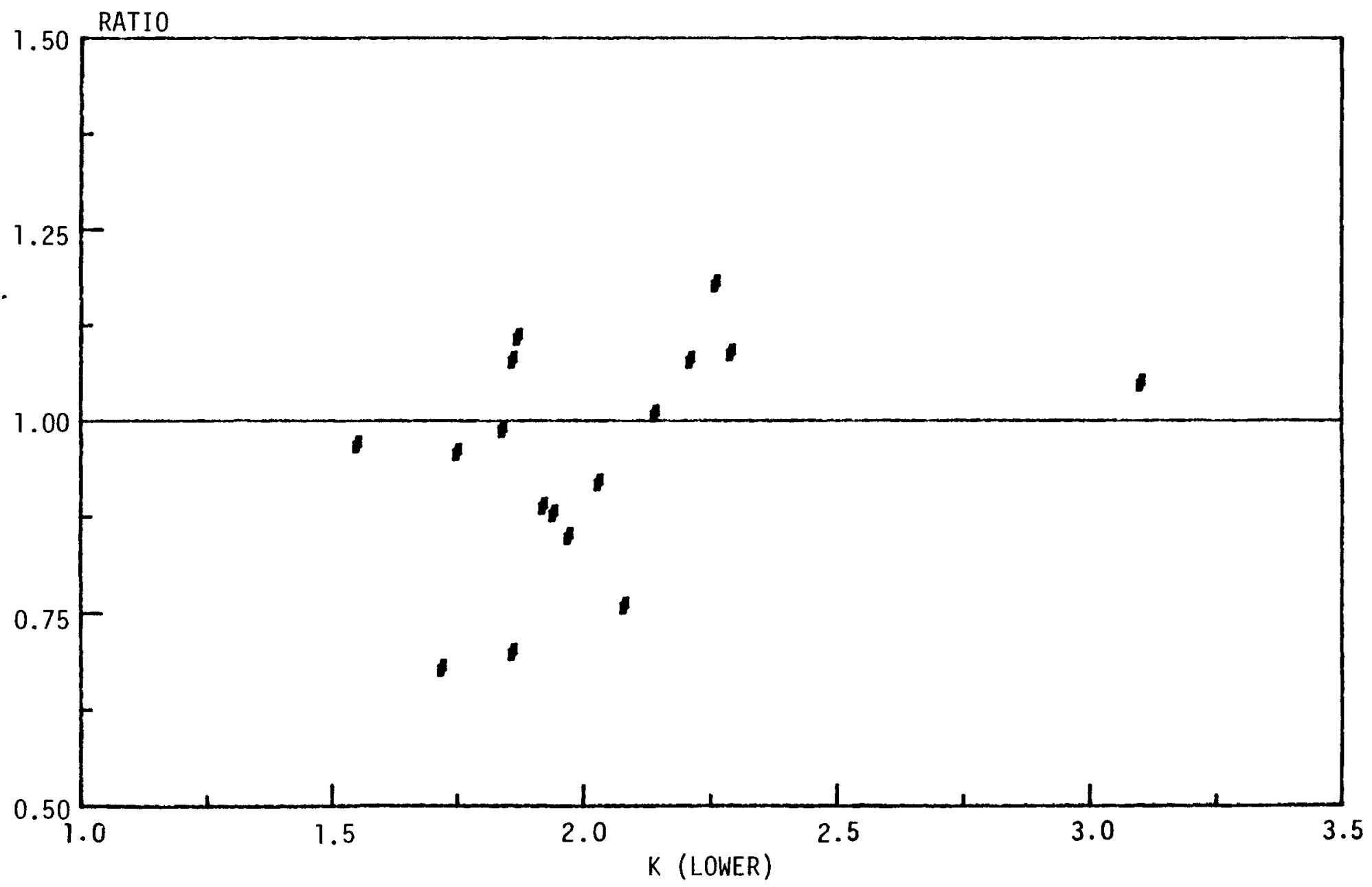

FIGURE 16. Ratio of Extrapolated to Measured $k$ Values for all Hours. Extrapolations are based on Equation (9). 


\section{RATIO OF EXTRAPOLATED TO MEASURED $K$}

MIETS

$\stackrel{\omega}{\omega}$

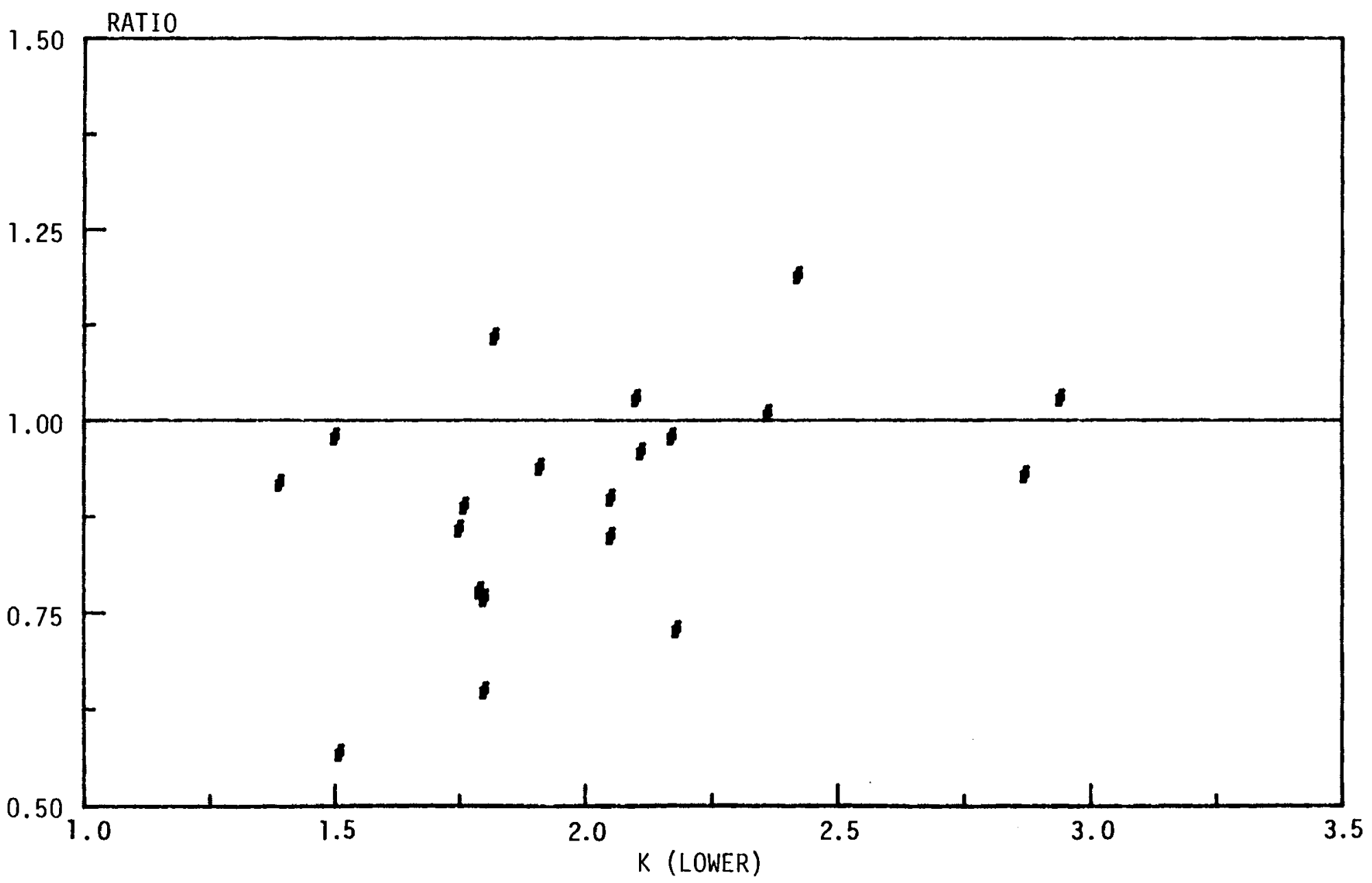

FIGURE 18. Ratio of Extrapolated to Measured $k$ Values for Night Hours. Extrapolations are based on Equation (9). 
TABLE 3. Ratios of Extrapolated and Measured Weibull Parameters. Extrapolations are based on Equations (8) through (10).

\begin{tabular}{|c|c|c|}
\hline Time & $c$ (pred)/c(meas) & $k$ (pred)/k(meas) \\
\hline $\begin{array}{l}\text { All Hours } \\
\text { Nights } \\
\text { Days }\end{array}$ & $\begin{array}{l}1.03 \pm 0.11 \\
0.96 \pm 0.13 \\
1.12 \pm 0.10\end{array}$ & $\begin{array}{l}0.96 \pm 0.14 \\
0.90 \pm 0.15 \\
1.10 \pm 0.15\end{array}$ \\
\hline
\end{tabular}

These systematic biases suggest that it may be possible to produce a somewhat improved extrapolation scheme by dividing the data into daylight and nighttime periods and applying a different extrapolation scheme to each. This is consistent with the behavior observed for power law coefficients earlier, as well as with the suggestion advanced by Heald and Mahrt (1981). However, the degree of scatter also implies that relatively little is to be gained by this approach.

An interesting characteristic of these data is the smaller scatter observed for the $c$ ratios than was found in the earlier study by Doran and Verholek (1978). The reason for this improvement is not known.

It should also be remarked that the extrapolation formulas for $c$ appeared to perform differently in simple and complex terrain. An example is shown in Figure 19, where $c$ ratios for nighttime hours are identified by terrain type. The ratios are noticeably lower for the simple terrain sites than for the complex ones, with values of $0.88 \pm 0.06$ and $1.06 \pm 0.13$, respectively. While similar behavior is observed for the $k$ ratios, with corresponding mean values of $0.87 \pm 0.17$ and $0.94 \pm 0.11$, the standard deviations are large enough that the difference in the means is not very significant. For daylight hours, even the differences in $c$ do not appear to be significant. The mean $c$ ratios for simple and complex terrain are $1.10 \pm 0.09$ and $1.14 \pm 0.12$, while the $k$ ratios are $1.15 \pm 0.15$ and $1.03 \pm 0.13$.

It is a bit dangerous to draw too strong a conclusion from any of these differences. Presumably the statistics are a function of the particular choice of sites chosen for analysis, especially for the complex terrain ones. 


\section{RATIO OF EXTRAPOLATED TO MEASURED C}

SIPPE NO COREX IERUIM MReTS

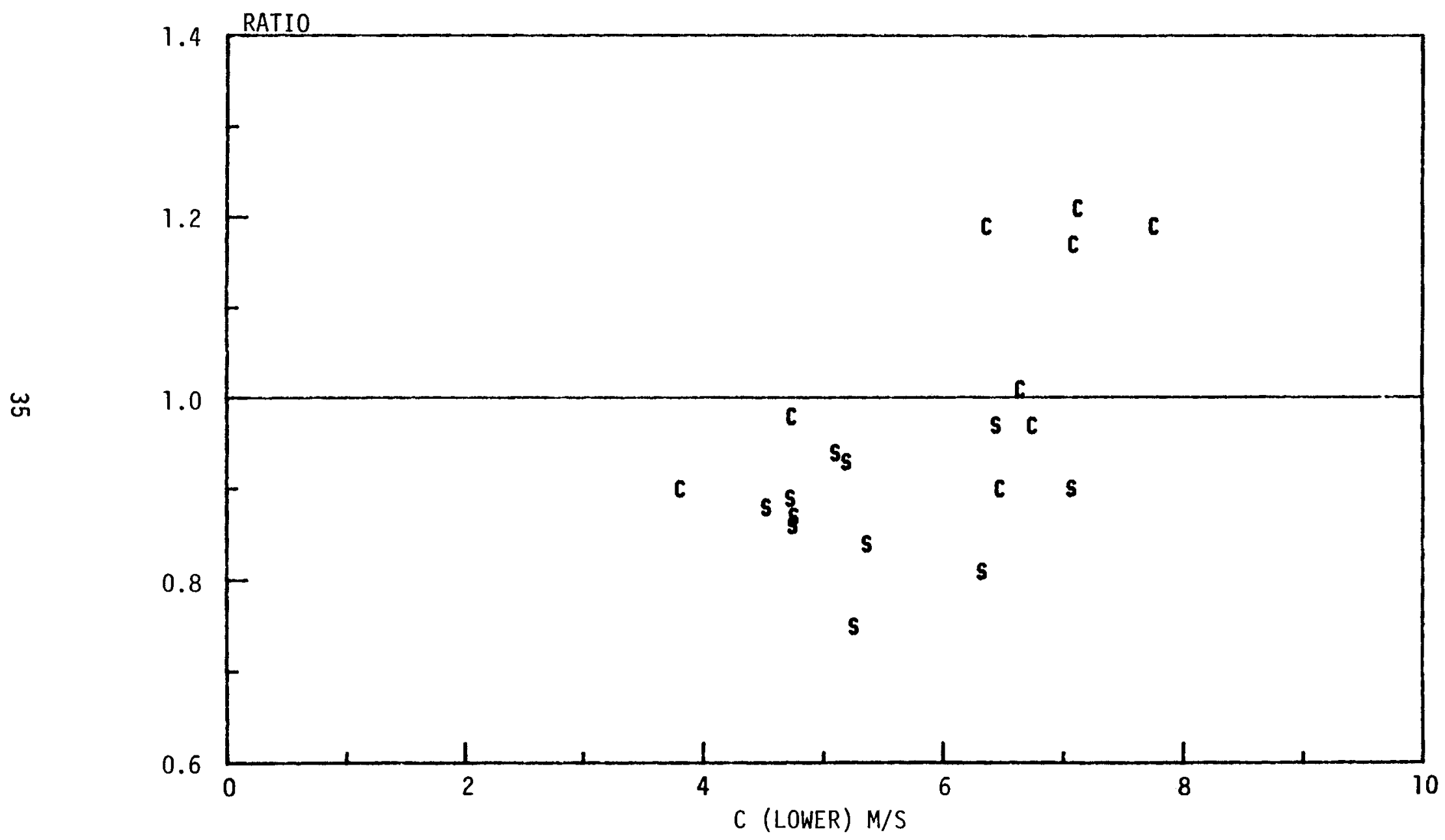

FIGURE 19. Ratio of Extrapolated to Measured $c$ Values for Simple (S) and Complex (C) Terrain for Night Hours 
Nonetheless, it does illustrate the point that behavior of wind profiles derived over flat, homogeneous terrain cannot be expected to be reproduced over more complicated topography. When this is coupled with the natural variability of the wind from year to year (e.g., Corotis, 1976), it seems foolhardy to rely on any extrapolation scheme for anything other than a coarse estimate of the wind speed distribution. There seems to be no satisfactory substitute for onsite measurements of some kind, and even these are subject to a fair degree of statistical uncertainty. 


\section{SIMULATION OF KITE MEASUREMENTS FOR WIND SPEED EXTRAPOLATIONS}

The use of kites as an economical means of obtaining wind speed distributions at elevated levels is a potentially attractive approach (e.g., Hewson and Baker, 1978; Martner and Gilmer, 1981). In this method, a relatively short meteorological tower provides long-term data, while intermittent kite flights are used to obtain information about associated upper-level winds. This information can be in the form of power law coefficients, which can then be used to extrapolate the lower-level wind speed distributions, or the kite data can be used directly to obtain wind speed distributions at higher elevations. These approaches are simulated in this section, and a discussion is given about the accuracy and reliability of these methods.

Data from the same sites described in Section 2 were used for the simulations. Nantucket Island, Massachusetts, was also added to this group. Each year's data was broken up into seasons, defined as follows:

Winter: December through February

Spring: March through May

Summer: June through August

Fal1 : September through November

Five consecutive days were chosen from each season to represent the sampling periods for the kite flights. To obtain a larger statistical base, a second time period was chosen six weeks later at each site. In several cases, missing data in one or the other period prevented a simulation from being made during those times; in all, 26 sets of measurements of 20 days duration were obtained. Hourly averaged data obtained from the $45.7-\mathrm{m}$ level of the towers were assumed to have been determined by kite flights during these periods. Power law coefficients were evaluated using these data, and a speed-dependent power law distribution similar to those described in Section 2 was derived for each site.

In practice, actual kite flights are more likely to be conducted during daylight hours. Consequently, distributions were obtained from data taken 
during daylight hours only. In addition, a second set of distributions was obtained using data taken around the clock during the 20 days of simulations. Each of these distributions was compared with the actual yearly distributions, using a normalized root mean square error.

$$
\text { normalized rms error }=\left\{\frac{1}{N} \sum_{i=1}^{N}\left(\frac{\alpha_{k}(i)-\alpha_{T}(i)}{\alpha_{T}(i)}\right)^{2}\right\}^{1 / 2}
$$

where $\alpha_{k}(i)$ is the $\alpha$ value obtained from the kite simulation, $\alpha_{T}(i)$ is the value determined from the full year's tower data, $i$ refers to the wind speed class, and $\mathrm{N}$ is the number of wind speed classes. Median wind speeds for the classes considered covered the range from 3 to $10 \mathrm{~m} / \mathrm{s}$. This selection avoided very low wind speeds, whose $\alpha$ values may be anomalously large but which normally make up only a small percentage of the winds at windy sites. The upper limit was chosen as a reasonably high value that could be expected to be found at all the sites a significant number of times. The results of this comparison are summarized in Table 4.

TABLE 4. Average Normalized Root Mean Square Errors of Kite-Simulated Distributions of $\alpha$

All Sites Simple Terrain Complex Terrain
Al1 Hours
$0.51 \pm 1.05$
$0.17 \pm 0.08$
$0.76 \pm 1.34$
Daylight Hours
$0.80 \pm 1.56$
$0.37 \pm 0.12$
$1.12 \pm 2.02$

Without Wells, Nevada, and San Augustine Pass, New Mexico:
Al1 Hours
$0.18 \pm 0.14$
$0.17 \pm 0.08$
$0.20 \pm 0.18$
Daylight Hours
$0.36 \pm 0.18$
$0.37 \pm 0.12$
$0.35 \pm 0.22$

The table is divided into two major sections. The upper section summarizes the results for all the sites, and shows that kite simulations yield much worse results in complex terrain than in simple terrain. This observation 
is misleading, however, as the results are heavily biased by values obtained at Wells, Nevada, and San Augustine Pass, New Mexico. There the $\alpha$ values are often quite smal1, which produces extremely large values of the expression in parentheses in Equation (11). If the values from these two sites are eliminated, the results are those shown in the second half of the table. In that section the results for the simple and complex terrain sites are much more similar, and the kite simulations work about equally well. Thus, the use of kites offers some possibility of obtaining useful estimates of the a distribution with wind speed, but as in all of the methods examined thus far, the scatter in the results suggests that such techniques be used with extreme caution.

Kites can be used not only to provide estimates of power law coefficient distributions but also to obtain estimates of wind speed distributions. To examine the utility of such methods, the same upper level data used for the determination of the $\alpha$ distributions were used to derive Weibull distributions of wind speed at the 45.7-m leve1. Hourly average wind speeds from the kite simulations were used to form a cumulative wind speed distribution at each of the sites. The Weibull scale factor $c$ and Weibull shape factor $k$ were then calculated from least squares fits to these cumulative probabilities at each site.

Figures 20 through 23 show the scatter diagrams of simulated and actual Weibull parameters; Figures 20 and 21 are comparisons of the scale and shape factors, respectively, for simulations based on observations taken at all hours for a 20-day period, while Figures 22 and 23 show similar comparisons but for simulations based on measurements made only during daylight hours. The solid line drawn in each figure corresponds to perfect agreement.

Table 5 summarizes this behavior in terms of the ratios of simulated to actual Weibull parameters. It may be useful to recall that the "daylight hours" entries refer to simulated kite flights carried out only during the days, but in all cases the parameters labeled "actual" were obtained from an analysis of a full year's data for all hours of the day. 


\section{WEIBULL SCALE FACTOR FOR ALL SITES}

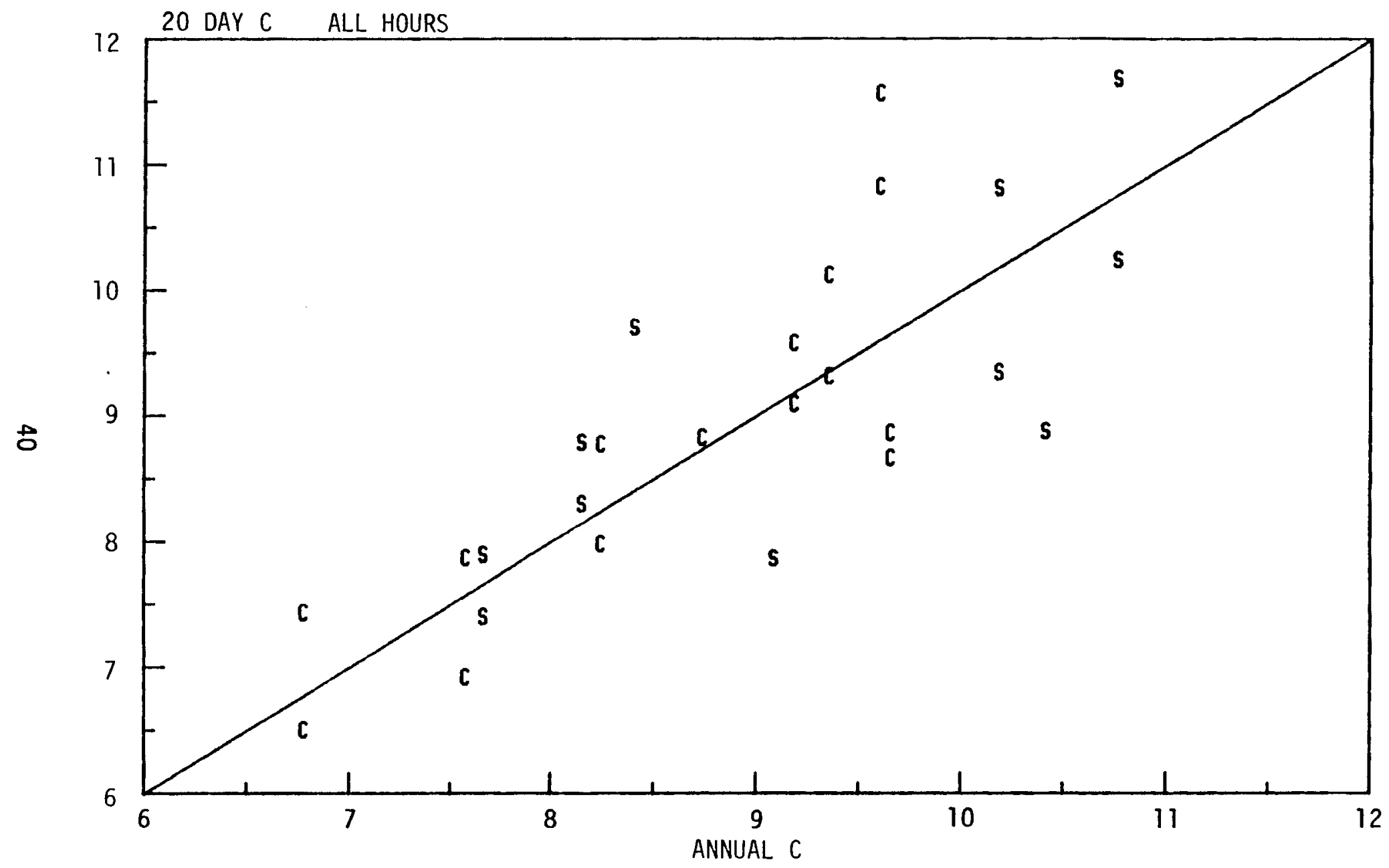

FIGURE 20. Comparison of Weibull Scale Factors, From Simulated Kite Flights During A1l Hours, With Actual Scale Factors for the Year; Simple Terrain Sites (S) and Complex Terrain Sites (C). Solid line indicates perfect agreement. 


\section{WEIBULL SHAPE FACTOR FOR ALL SITES}

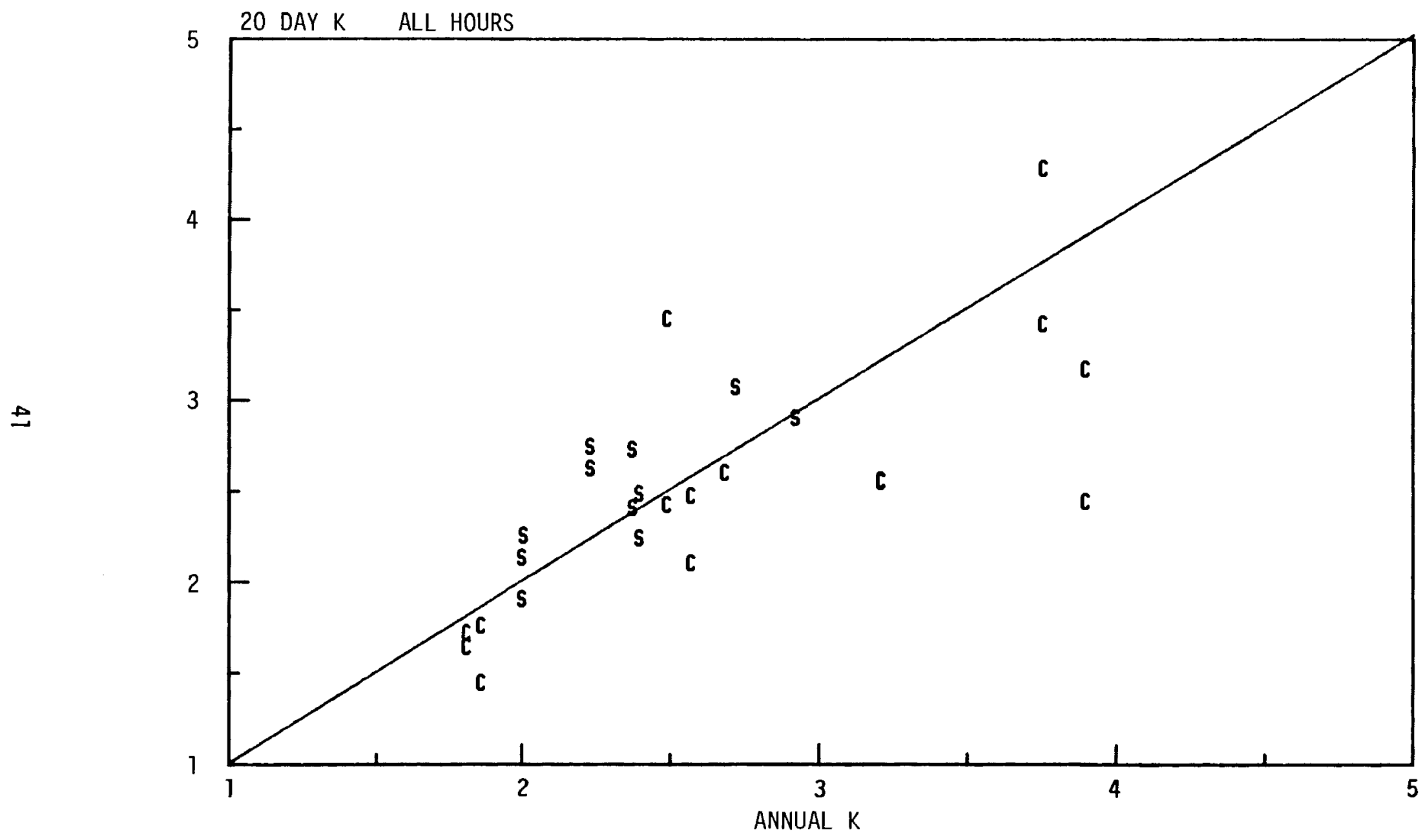

FIGURE 21. Comparison of Weibull Shape Factors, From Simulated Kite Flights During All Hours, With Actual Shape Factors for the Year; Simple Terrain Sites (S) and Complex Terrain Sites (C). Solid line indicates perfect agreement. 


\section{WEIBULL SCALE FACTOR FOR ALL SITES}

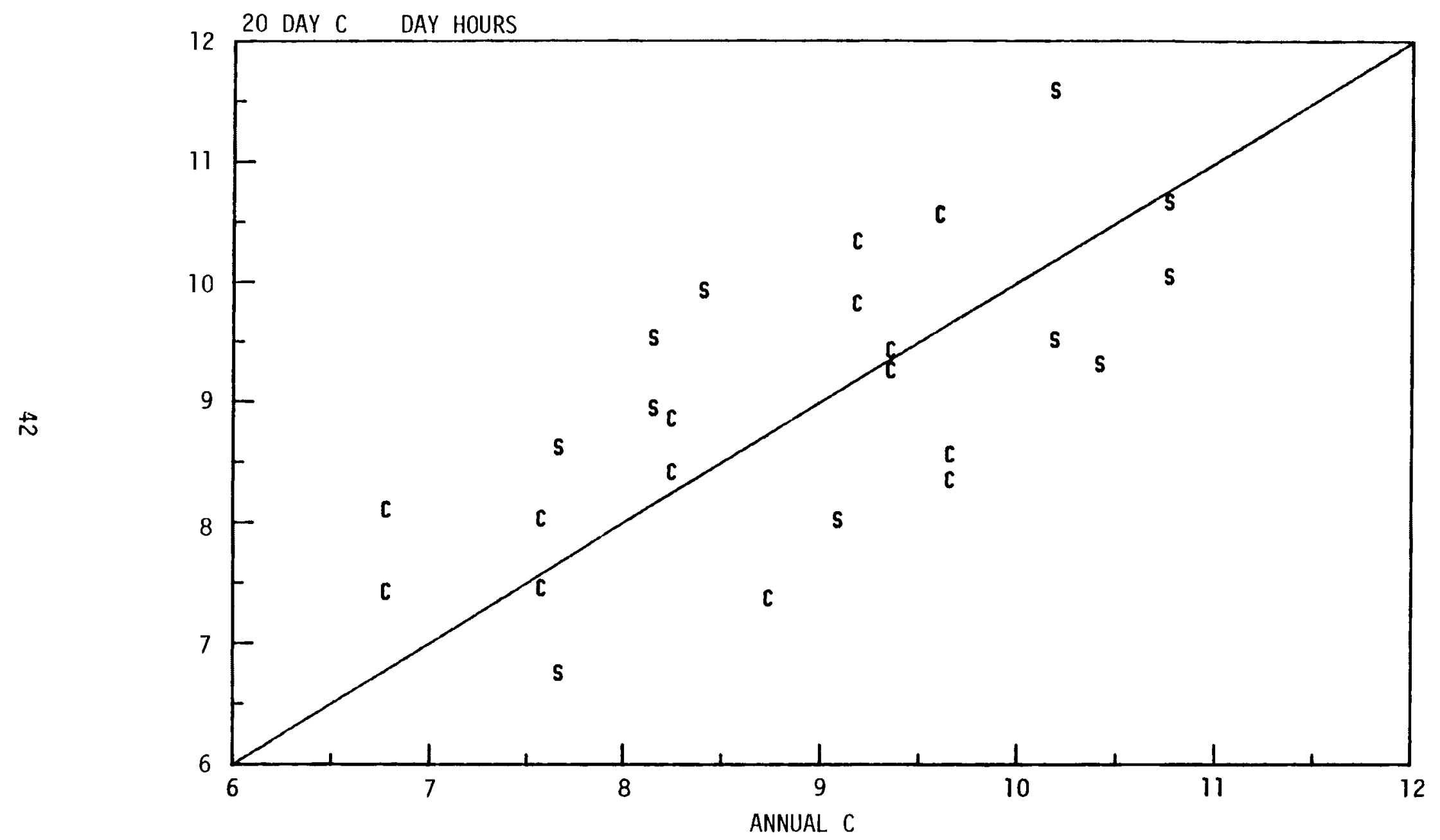

FIGURE 22. Comparison of Weibull Scale Factors, From Simulated Kite Flights During Daylight Hours, With Actual Scale Factors for the Year; Simple Terrain Sites (S) and Complex Terrain Sites (C). Solid line indicates perfect agreement. 
WEIBULL SHAPE FACTOR FOR ALL SITES

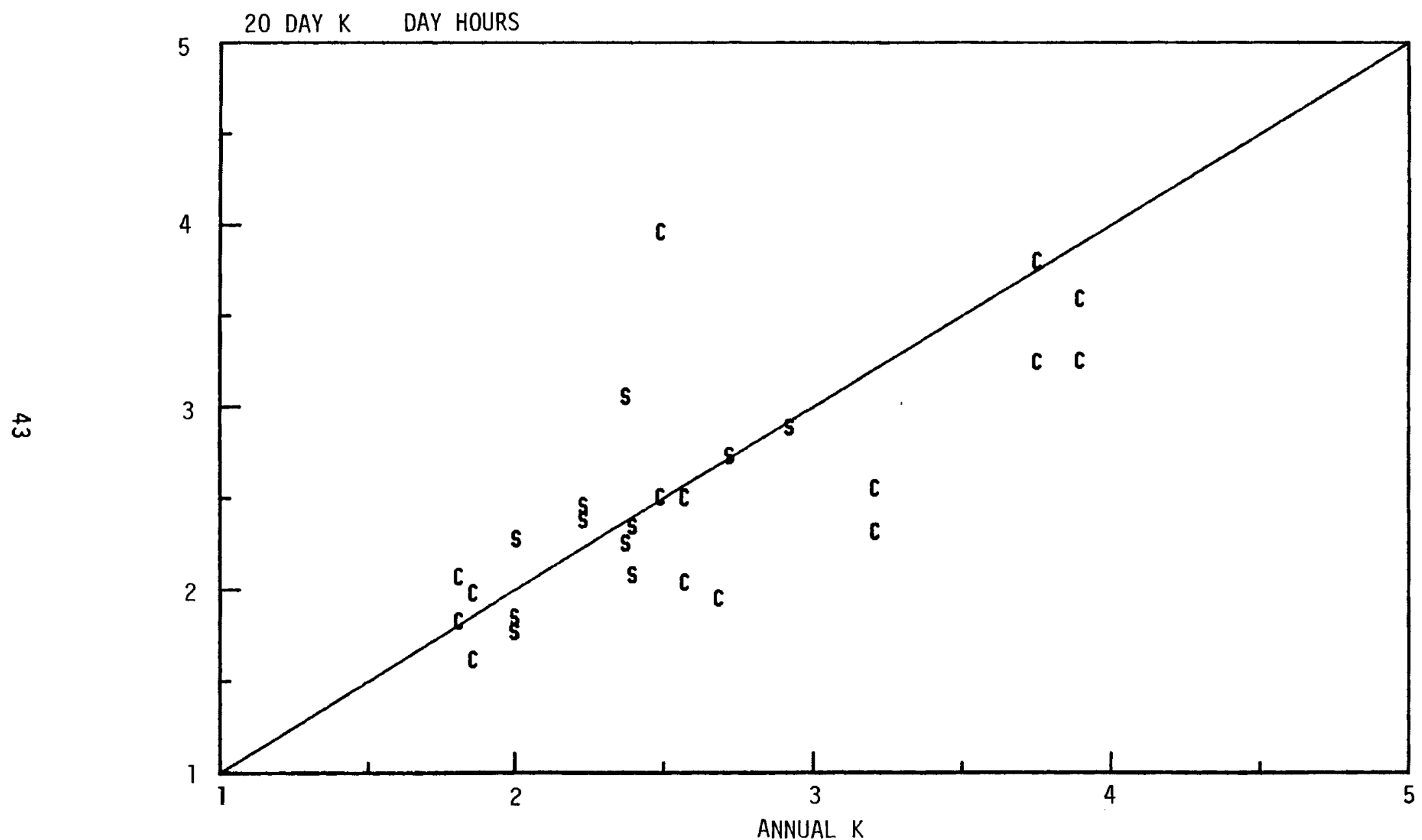

FIGURE 23. Comparison of Weibull Shape Factors, From Simulated Kite Flights During Daylight Hours, With Actual Shape Factors for the Year; Simple Terrain Sites (S) and Complex Terrain Sites (C). Solid line indicates perfect agreement. 
TABLE 5. Ratios of Simulated to Actual Weibull Parameters. Simulated parameters are derived from wind speed distributions as approximated by simulated kite measurements.

Al1 Hours

All Sites Simple Terrain Complex Terrain

$\begin{array}{llll}\overline{c(\text { simu }) / \overline{c(a c t u a ~})} & 1.01 \pm 0.09 & 1.00 \pm 0.10 & 1.02 \pm 0.08 \\ \overline{k(s i m u 1) / \overline{k(a c t u a) ~}} & 0.97 \pm 0.16 & 1.08 \pm 0.10 & 0.92 \pm 0.18\end{array}$

Daylight Hours

$\begin{array}{llll}\overline{c(\text { simu }) / \overline{c(a c t u a 1)}} & 1.01 \pm 0.11 & 1.02 \pm 0.12 & 1.03 \pm 0.10 \\ \overline{k(s i m u 1) / \overline{k(a c t u a 1)}} & 0.97 \pm 0.18 & 1.02 \pm 0.12 & 0.96 \pm 0.22\end{array}$

The simulations using assumed 24 -hour kite flights generally show slightly smaller standard deviations about the mean values of the ratios than the results obtained from the daylight flights. The means of the ratios show no clear tendencies of this kind. This is a bit surprising, and considering the sizes of the standard deviations, there appears to be less benefit to be gained by using the full 24-hour flights than might have been anticipated.

A particularly good example of this characteristic can be seen in Figures 24 and 25 . The former figure gives the actual fitted Weibull distribution for Livingston, Montana, along with fitted Weibull distributions from simulated kite data. In this case, the "all hours" data give clearly better agreement with the "true" Weibull fit than do the "daylight hours" data. Figure 25 shows equivalent plots of distributions for Minot, North Dakota; in this case, the relative performances of the "all hours" and "daylight hours" simulations are interchanged.

In the approach discussed above, Weibull parameters were calculated by using kite data to estimate cumulative frequency distributions of wind speeds at kite level. An alternative approach is to use the power law exponent distributions derived from kite data to extrapolate the wind speed distribution of the lower level to a second distribution at the upper level. By equating 


\section{WEIBULL PROBABILITY DISTRIBUTION}

Luvinaston, MT

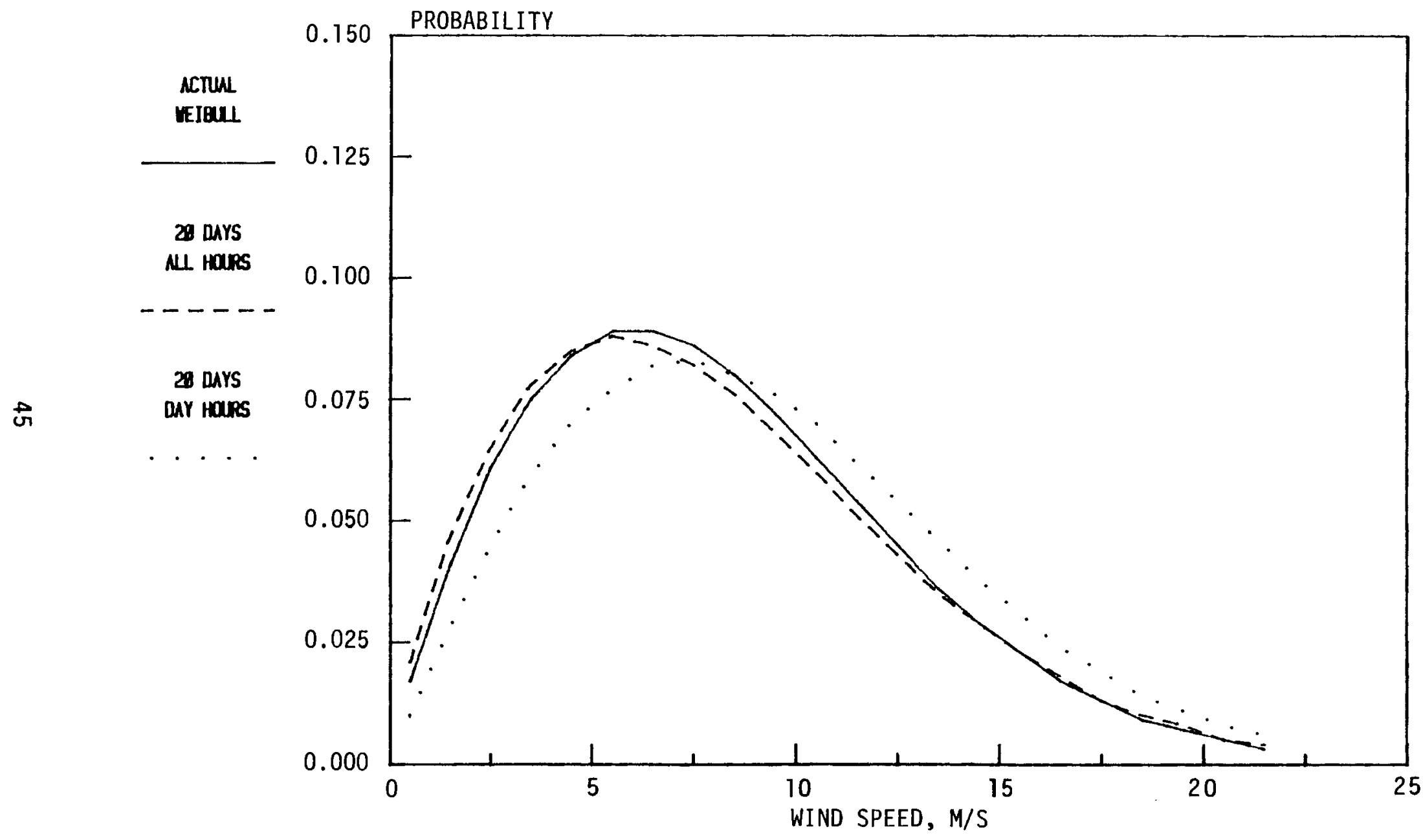

FIGURE 24. Weibul1 Distributions for Livingston, Montana, Using Actual Hourly Data for the Year and Simulated Kite Data for all Hours and for Daylight Hours 


\section{WEIBULL PROBABILITY DISTRIBUTION}

MINOT. M

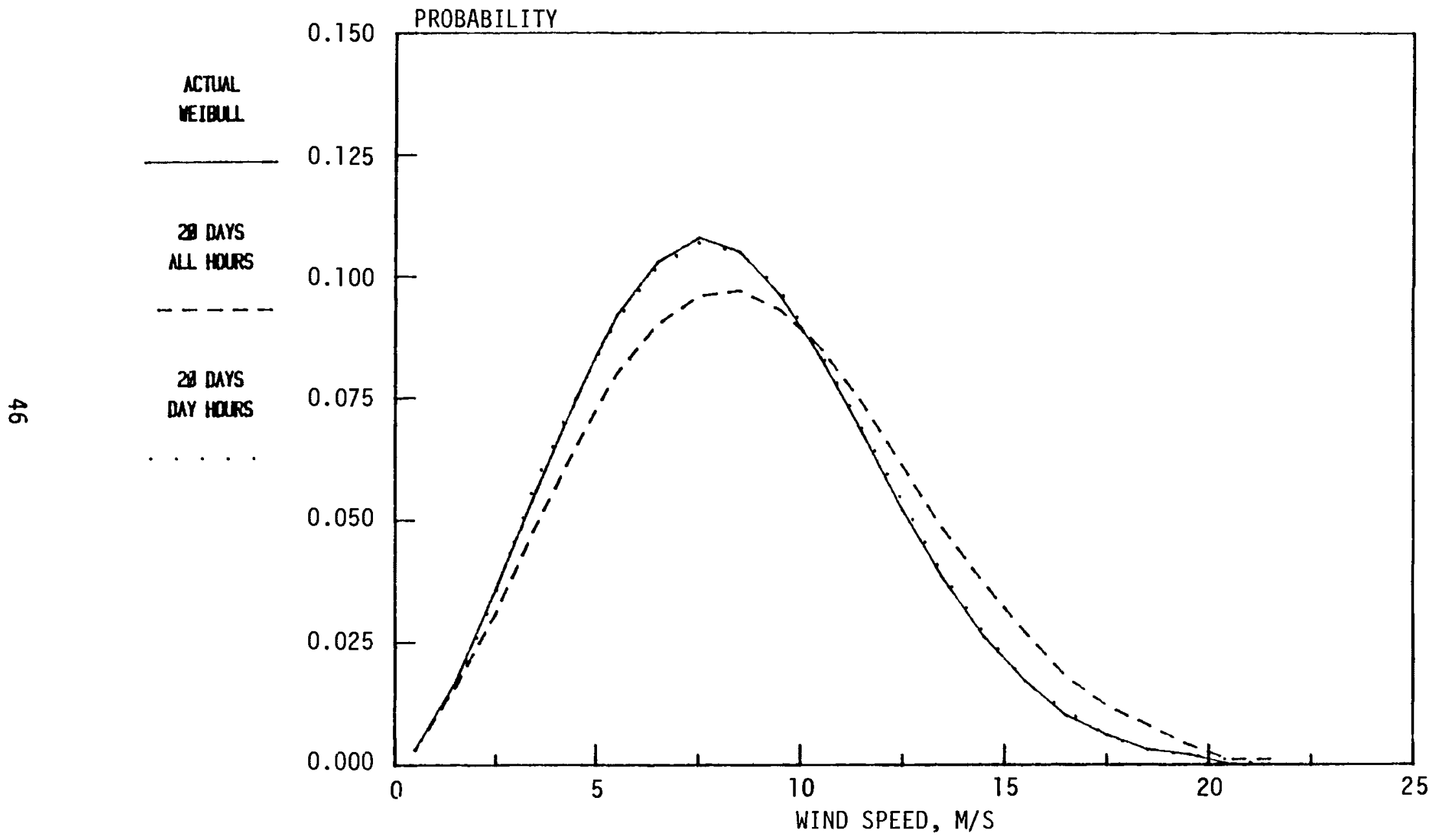

FIGURE 25. Weibu11 Distributions for Minot, North Dakota, Using Actual Hourly Data for the Year and Simulated Kite Data for all Hours and for Daylight Hours 
the cumulative probability of a given wind speed at the lower level to the cumulative probability of the extrapolated speed at the upper level, the new distribution can be found. This distribution can, in turn, be fit to a Weibul1 distribution for ease of comparison.

Scatter diagrams for the actual Weibull parameters and those derived from these extrapolations are shown in Figures 26 through 29 . Figures 26 and 27 are for Weibull scale and shape parameters, respectively, calculated using as obtained for all hours for 20 days, while Figures 28 and 29 show corresponding behavior for a distributions derived from daylight flights alone. The ratios of the simulated to actual Weibull parameters obtained by this method are shown in Table 6 .

Although the standard deviations about the means for the $c$ simulations are better than those found in Table 5, the means themselves are not as good. The ratios for the $k$ values are generally poorer than those for the $c$ values, and the daylight-derived a distributions yield generally unsatisfactory results for both $k$ and $c$.

There are, then, three possible schemes for determining Weibull distributions at higher elevations without actually collecting long-term data there. The first is the use of the extrapolation formulas given in Section 3 . The second is to use kites for a limited period of time to obtain direct estimates of the wind speed distributions, and the third is to use kites to obtain $\alpha$ distributions, which may then be used to extrapolate the low-level wind speed distributions. Based on the means and standard deviations of the ratios of extrapolated to actual $c$ and $k$ values, there is relatively little to distinguish which of these three approaches would give the most accurate results. For $c$ ratios, the kite-derived a distributions do perform marginally better. A further examination shows that the use of the extrapolation formula results in some significant outliers; for example, over $20 \%$ of the c ratios differed from unity by $18 \%$ or more. In contrast to this, the use of kite-measured as for 24-hour periods gave only one ratio (out of 26) that differed from unity by more than $20 \%$ and only two others that differed by $15 \%$. In this sense, the use of measured $\alpha$ distributions derived from kites seems to be the most 
accurate of the three, and the least likely to result in large errors. However, the differences are small, the expense is considerably greater for flying kites than for simple extrapolations, and none of these approaches is an adequate substitute for long-term measurements. It must also be kept in mind that the techniques discussed above are actually methods to obtain approximations to an approximation. The Weibull fit is subject to the same errors as any statistically derived probability distribution and cannot be expected to adequately describe the wind speed distribution at all sites for all conditions.

TABLE 6. Ratios of Simulated to Actual Weibull Parameters. Simulated parameters are derived from extrapolation of lower-level wind speed distributions using kite-derived alpha distributions.

A11 Hours All Sites Simple Terrain Complex Terrain
c(simul)/c(actual)
$0.96 \pm 0.05$
$0.96 \pm 0.07$
$0.96 \pm 0.04$
$\bar{k}(\operatorname{simu}) / \overline{k(\text { actua })}$
$0.98 \pm 0.18$
$1.06 \pm 0.12$
$0.93 \pm 0.19$

Dayl ight Hours

\begin{tabular}{|c|c|c|c|}
\hline$\overline{c(\operatorname{simu})} / \overline{c(\text { actua })}$ & $0.89 \pm 0.07$ & $0.85 \pm 0.06$ & $0.93 \pm 0.05$ \\
\hline$k(\operatorname{simu}) / \bar{k}($ actua $)$ & $0.87 \pm 0.18$ & $0.86 \pm 0.07$ & $0.89 \pm c$ \\
\hline
\end{tabular}




\section{WEIBULL SCALE FACTOR FOR ALL SITES}

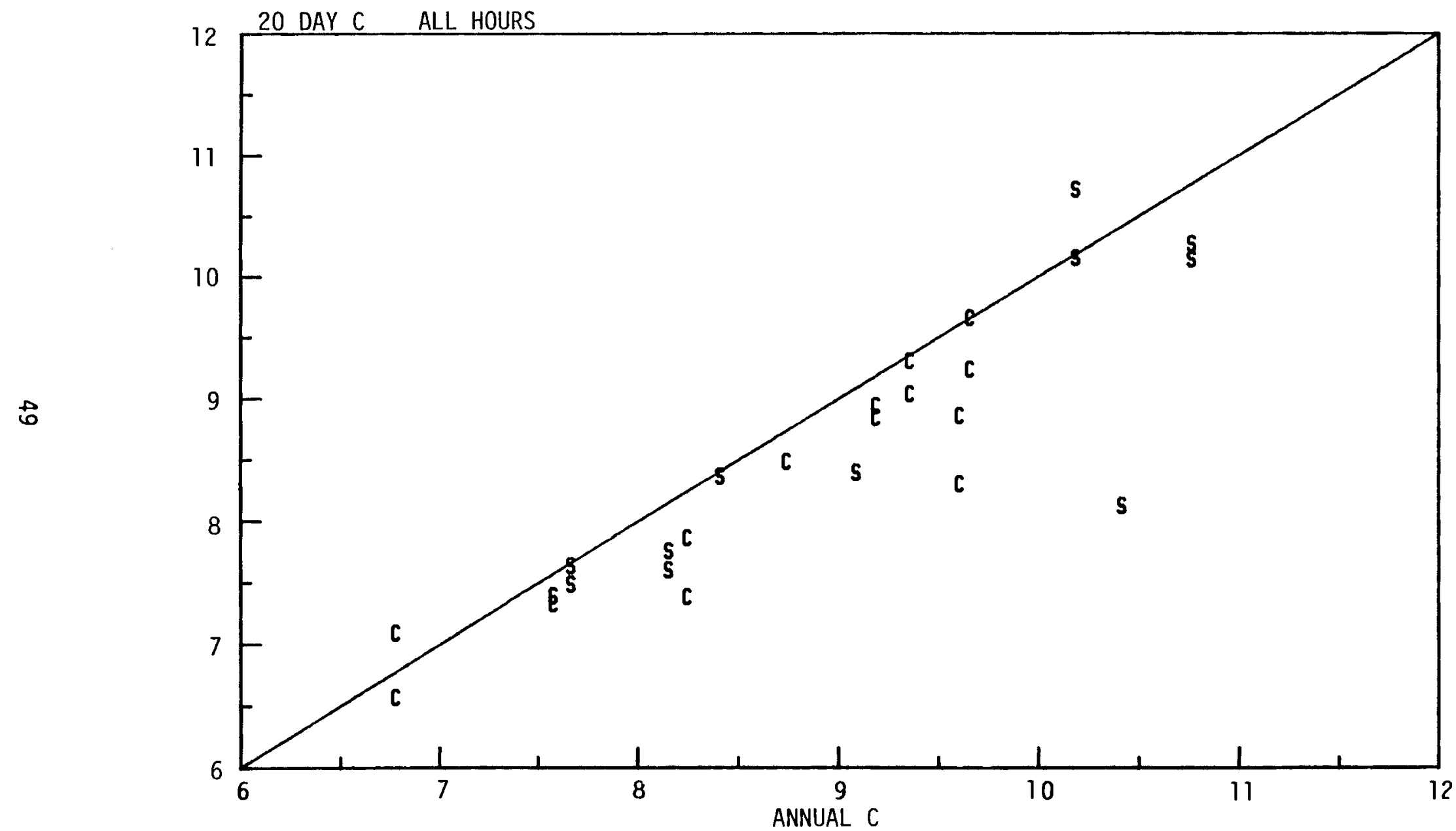

FIGURE 26. Comparison of Weibull Scale Factors, From Simulated Kite Flight Alpha Distributions for all Hours, With Actual Scale Factors for the Year; Simple Terrain Sites (S) and Complex Terrain Sites (C). Solid line indicates perfect agreement. 


\section{WEIBULL SHAPE FACTOR FOR ALL SITES}

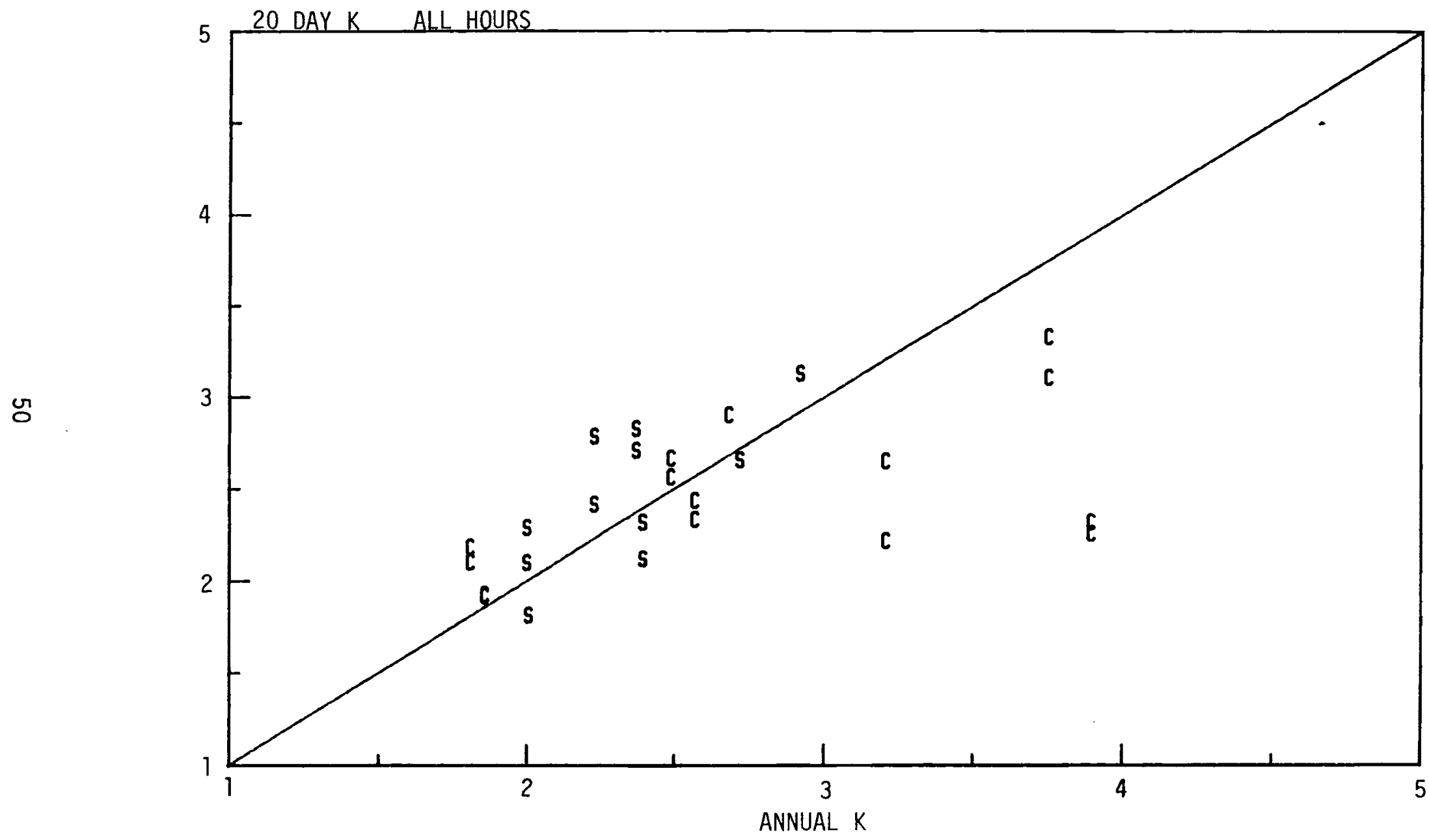

FIGURE 27. Comparison of Weibull Shape Factors, From Simulated Kite Flight Alpha Distributions for all Hours, With Actual Shape Factors for the Year; Simple Terrain Sites (S) and Complex Terrain Sites (C). Solid line indicates perfect agreement. 


\section{WEIBULL SCALE FACTOR FOR ALL SITES}

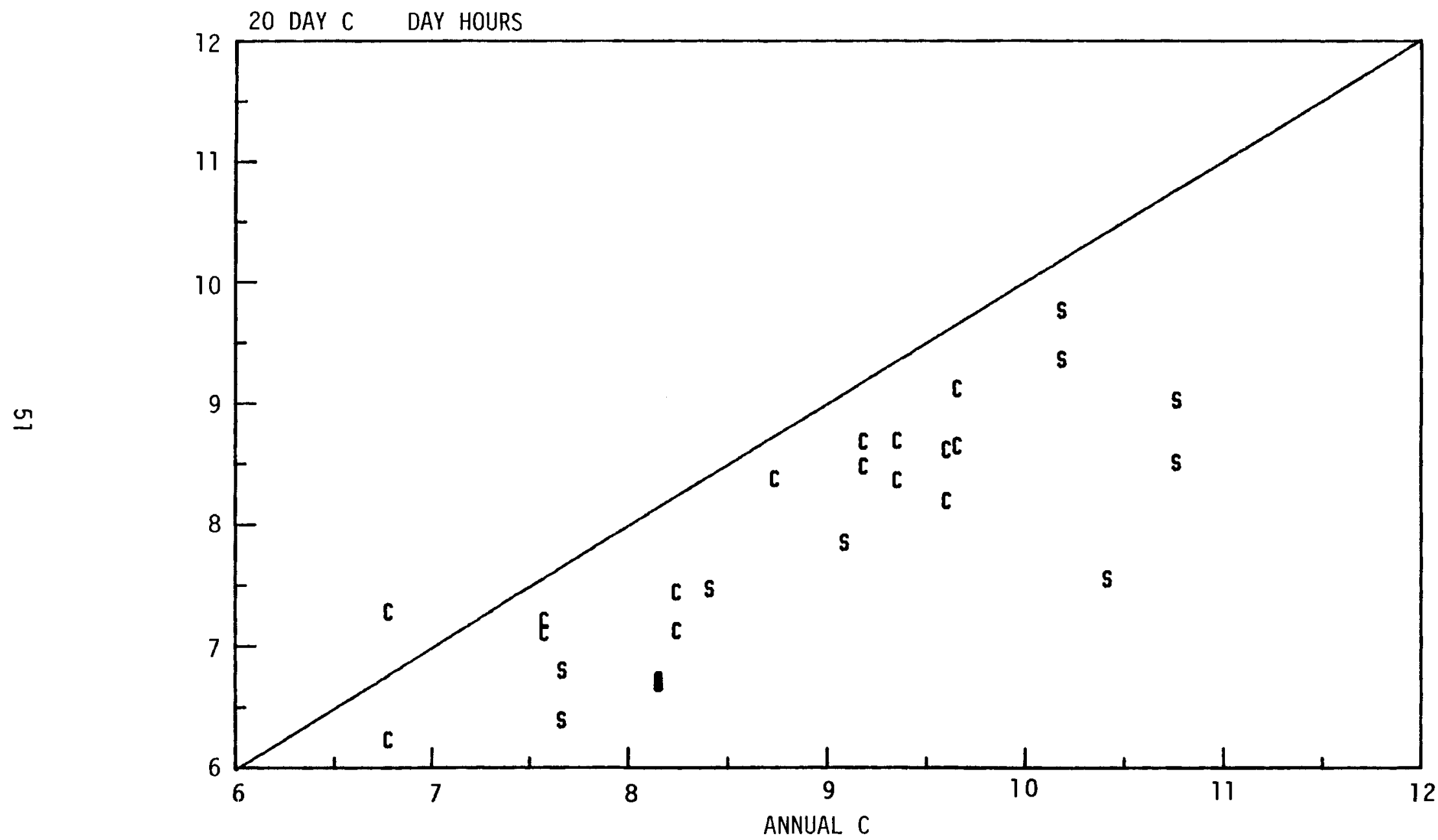

FIGURE 28. Comparison of Weibull Scale Factors, From Simulated Kite Flight Alpha Distributions for Daylight Hours, with Actual Scale Factors for the Year; Simple Terrain Sites (S) and Complex Terrain sites (C). Solid line indicates perfect agreement. 


\section{WEIBULL SHAPE FACTOR FOR ALL SITES}

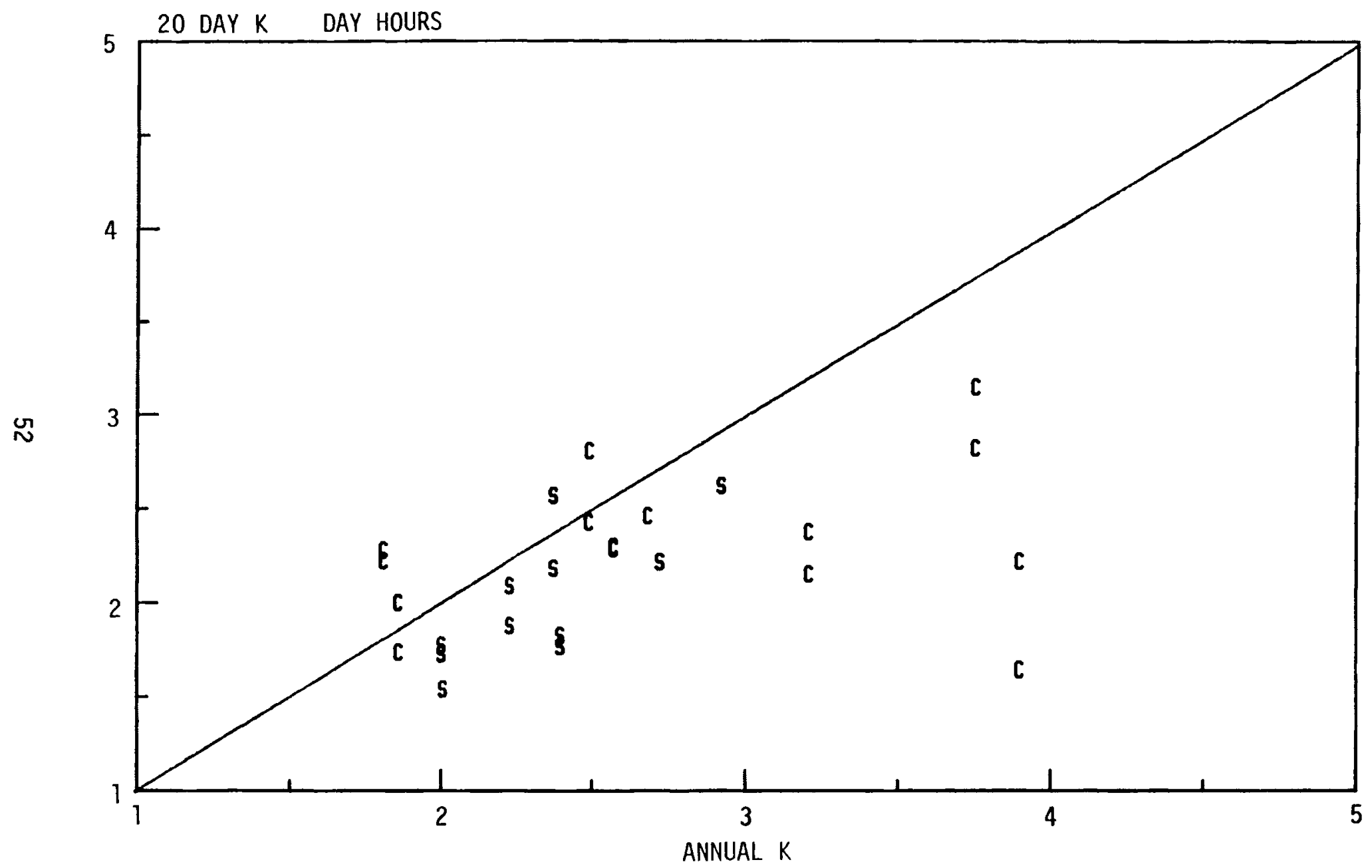

FIGURE 29. Comparison of Weibull Shape Factors, From Simulated Kite Flight Alpha Distributions for Daylight Hours, With Actual Shape Factors for the Year; Simple Terrain Sites (S) and Complex Terrain Sites $(C)$. Solid line indicates perfect agreement. 


\section{RECOMMENDATIONS}

The conclusions to be drawn from the previous discussions are quite basic and quite simple. The power law approach to wind speed extrapolations seems inherently incapable of reliably predicting the variation of wind speed with height for a general case. There can be a considerable amount of scatter even in simple terrain. If the purposes for which a wind speed distribution is required are at all dependent upon an accurate determination of that distribution, then some other method should be used to estimate it. Perhaps the best candidate is a direct measurement of some sort. If the purposes are more general, e.g., a rough estimate of wind power potential over a broad area, then the use of extrapolation formulas may be justified. Additional investigations along the lines described in this report are not suggested. 



\section{REFERENCES}

Corotis, R. B. 1977. Stochastic Modelling of Site Wind Characteristics. Final Report, RLO/2342-77/2, 143 pp., available from NTIS, Springfield, Virginia.

Doran, J. C., J. A. Bates, P. J. Lidde11, T. D. Fox. 1977. Accuracy of Wind Power Estimates. PNL-2442, Pacific Northwest Laboratory, Richland, Washington.

Doran, J. C. and M. G. Verholek. 1978. "A Note on Vertical Extrapolation Formulas for Weibul1 Velocity Distribution Parameters." J. of Applied Meteor., 17:410-412.

Heald, R. C. and L. Mahrt. 1981. "The Dependence of Boundary-Layer Shear on Diurnal Variation of Stability." J. of Applied Meteor., 20:859-867.

Hewson, E. W. and R. W. Baker. 1978. Wind Power, Network Wind Power Over the Pacific Northwest. Report No. BPA 77-2 to Bonneville Power Administration, PortTand, Oregon.

Justus, C. G. and A. Mikhail. 1976(a). "Height Variation of Wind Speed and Wind Distribution Statistics." Geophys. Res. Lett., 3:261-264.

Justus, C. G., W. R. Hargraves and A. Mikhai1. 1976(b). Reference Wind Speed Distributions and Height Profiles for Wind Turbine Design and Performance Evaluation Applications. ORO/5108-76/4, available from NTIS, Springfield, Virginia.

Martner, B. E. and J. W. Gilmer. 1981. Wind Characteristics in Southern Wyoming, Part II: Vertical Profiles. Report No. AS 128, Department of Atmospheric Sciences, University of Wyoming, Laramie, Wyoming.

Mikhai1, A. 1977. Atmospheric Boundary Layer Similarity Theory for Applications in Wind Energy Fields. Thesis, Georgia Institute of Technology, Atlanta, Georgia.

Mikhai1, A. 1982. Height Extrapolation of Wind Data. PNL-4367, Pacific Northwest Laboratory, Richland, Washington.

Panofsky, H. A. 1977. "Wind Structure in Strong Winds Below 150-m." Wind Engineering, 1:91-103.

Peterson, E. W. 1969. "Modification of Mean Flow and Turbulent Energy by a Change in Surface Roughness Under Conditions of Neutral Stability."

Quart. J. Roy. Met. Soc., 95:561-575. 
Rao, K. S., J. C. Wyngaard and 0. R. Cote. 1974. "The Structure of the TwoDimensional Internal Boundary Layer Over a Sudden Change of Surface Roughness." J.Atmos. Sci., 31:738-746.

Renne, D. S. and W. F. Sandusky. 1980. "DOE Candidate Site Meteorological Measurement Program." Presented at the Third Meeting of Experts Data Acquisition and Analys is for Large-Scale Wind Energy Conversion Systems, Blowing Rock, North Carolina, September 26-27, 1979.

Spera, D. A. and T. R. Richards. 1979. "Modified Power Law Equations for Vertical Wind Profiles." Proceedings of the Conference and Workshop on Wind Energy Characteristics and Wind Energy Siting 1979. American Meteorological Society, Boston, Massachusetts.

Touma, J. S. 1977. "Dependence of the Wind Profile Power Law on Stability for Various Locations. J. of the Air Poll. Con. Assoc., 863-866. 


\section{DISTRIBUTION}

No. of

Copies

\section{OFFSITE}

C. I. Aspliden

Battelle Memorial Institute Washington Operations Office 2030 M Street, N.W. Washington, DC 20036

S. D. Berwager Department of Energy Wind Energy Technology Division 1000 Independence Avenue Forrestal Building, Room 5F059 Washington, DC 20585

\section{Jack Cadogan}

Department of Energy

Wind Energy Technology Division

Forrestal Building, Room 5F069

1000 Independence Avenue, S.W. Washington, DC 20585

L. V. Divone

Department of Energy

Wind Energy Technology Division

1000 Independence Avenue

Forrestal Building, Room 5F059

Washington, DC 20585

G. P. Tennyson

Department of Energy

A]buquerque Operations Office

P.0. Box 5400

Albuquerque, NM 87115

27 DOE Technical Information Center

Fred Whitson

Bendix Field Engineering Corp.

2582 South Tejon

Englewood, CO 80110
No. of

Copies
Don Nielson

MS-9A-65

Boeing Engineering and

Construction, Co.

P.0. Box 3707

Seattle, WA 98124

Nicholas Butler

Bonneville Power Administration

P.0. Box 3621

Portland, OR 97208

T. D. Younkins

General Electric Systems

Engineering Department

General Electric Company

1 River Road

Schenectady, NY 12345

Stanley Macklis

General Electric, Co.

Advanced Energy Systems

P.0. Box 8661

Philadelphia, PA 19101

J. M. Kos

Hamilton Standard

Bradley Field Road

Windsor Locks, CT 06096

David Spera

NASA/Lewis Research Center

21000 Brookpark Road

Cleveland, $\mathrm{OH} \quad 44135$

D. L. W. Reddoch

Oak Ridge National Laboratory

P.0. Box $X$

Oak Ridge, TN 37830 
No. of

Copies

R. Thresher

Department of Mechanical Engr. Oregon State University

Corvallis, OR 97331

J. P. Sullivan

School of Aero \& Astronautics

331 Grissom Hall

Purdue University

West Lafayette, IN 47907

A. C. Hansen

Rockwell International

P.0. Box 464

Golden, CO 80401

E. G. Kadlec

Sandia Labs 4715

Box 5800

Albuquerque, NM 87165

S. M. Chan

Systems Control, Inc. 1801 Page Mill Road

P.0. Box 10025

Palo Alto, CA 94303

T. Anderson

Westinghouse Electric Co.

P.0. Box 10824

Pittsburgh, PA 15236

R. H. Kirchhoff

Department of Mechanical Engr. University of Massachusetts

Amherst, MA 01003

A. B. Van Rennes

The Bendix Corporation

Executive Offices

Bendix Center

Southfield, MI 48037
No. of

Copies

H. Tieleman

Department of Engineering Science

\& Mechanics

Virginia Polytechnic Institute and State University

Blacksburg, VA 24061

R. E. Akins

Wind Energy Division 4715

Sandia National Laboratories

Albuquerque, NM 87185

Dr. Neil Cherry

Lincoln College

Canterbury

NEW ZEALAND

ONSITE

1 DOE Richland Operations Office

H. E. Ransom

46 Pacific Northwest Laboratory

W. R. Barchet

W. C. Cliff

J. R. Connell

J. C. Doran

C. E. Elderkin

A. H. Miller

E. L. Owczarski

W. T. Pennell

D. C. Powe 11

J. V. Rams de 11

D. S. Renné

H. L. Wegley

L. L. Wendell

R. K. Woodruff

Technical Information Files (5)

Publishing Coordination (2)

WCPE Program Office (15)

2400 Stevens Library (10) 